\title{
THE STRUCTURE AND PROPERTIES OF TRANSITION METAL-METALLOID GLASSES BASED ON REFRACTORY METALS
}

W. L. Johnson and A. R. Williams

JANUARY 1979

A REPORT ON RESEARCH CONDUCTED

UNDER CONTRACT FOR THE

DEPARTMENT OF ENERGY

W. M. KECK LABORATORY OF

ENGINEERING MATERIALS

CALIFORNIA INSTITUTE OF TECHNOLOGY

PASADENA 


\section{DISCLAIMER}

This report was prepared as an account of work sponsored by an agency of the United States Government. Neither the United States Government nor any agency Thereof, nor any of their employees, makes any warranty, express or implied, or assumes any legal liability or responsibility for the accuracy, completeness, or usefulness of any information, apparatus, product, or process disclosed, or represents that its use would not infringe privately owned rights. Reference herein to any specific commercial product, process, or service by trade name, trademark, manufacturer, or otherwise does not necessarily constitute or imply its endorsement, recommendation, or favoring by the United States Government or any agency thereof. The views and opinions of authors expressed herein do not necessarily state or reflect those of the United States Government or any agency thereof. 


\section{DISCLAIMER}

Portions of this document may be illegible in electronic image products. Images are produced from the best available original document. 
California Institute of Technology

W. M. Keck Laboratory of Engineering Materials

THE STRUCTURE AND PROPERTIES OF This report was prepared as an account of wer the sponsored by the United United States Department of United States nor the Energy, nor any of their er their employees, makes contractors, subcontro or implied, or assumes any legal any warranty, express or for the accuracy, compieteness liability or responsiolity for the aparatus, product or or usefulness of any tiformats the its use would not

process disclased, of represents
infringe privately owned rights.

TRANSITION METAL-METALLOID GLASSES

BASED ON REFRACTORY METALS

by

W. L. Johnson and A. R. Williams

DISTRIBUTION OF THIS DOCUMENT IS UNLIBITERQ

Department of Energy Report No. 94, under Contract No. EY-76-C-03-0822

Professor W. L. Johnson, principal investigator. 
NOTICE

This report was prepared as an account of work sponsored by the United States Government. Neither the United States nor the Department of Energy, nor any of their employees, nor any of their contractors, subcontractors, or their employees, makes any warranty, express or implied, or assumes any legal liability or responsibility for the accuracy, completeness or usefulness of any information, apparatus, product or process disclosed, or represents that its use would not infringe privately-owned rights. 
ABSTRACT

The structure and properties of several new transition metalmetalloid $\left(\mathrm{TM}_{1-x} \mathrm{M}_{\mathrm{x}}\right)$ metallic glasses based on refractory transition metals (e.g. Mo, wo Ru etc.) have been systematically investigated as a function of composition. The structure of the alloys has been investigated by $x$-ray diffraction methods and measurements of superconducting properties, electrical resistivity, density, hardness, and mechanical behavior were carried out. These data are used in developing a novel description of the structure of $\mathrm{TM}_{1-x} \mathrm{M}_{x}$ glasses. The experimental evidence suggests that an ideal amorphous phase forms at a specific composition $x_{c}$ and that this phase has a well defined atomic short range order. For metallic glasses having $x<x_{c}$ (metalloid poor glasses) "vacancy-like". defects form, which are characterized by the excess volume which they contribute to the glass. Another, as yet unspecified defect appears to form in glasses with $x>x_{c}$. This novel picture can explain the variation of many properties of these glasses with metalloid concentration. 


\section{INTRODUCTION}

Since the early work of Duwez and his colleagues ${ }^{1}$ on the rapid solidification of liquid metals, a large number of alloys have been prepared as metallic glasses. One large family of metallic glasses consists of alloys having the general formula (TM) $1-x{ }^{M} x$ where TM refers to a transition metal(s) and $M$ to a non-transition element (metalloid) chosen from group $A$ of the periodic table. The composition $x$ is typically in the range $(0.1<x<0.3)$. Extensive efforts have been made to characterize the atomic-scale structure of these glassy alloys and to relate this structure to observed physical properties. ${ }^{2}$ In a recent publication ${ }^{3}$, it was reported that alloys of the form $\left(\mathrm{Mo}_{1-y} \mathrm{Ru}_{y}\right)_{80} \mathrm{P}_{20}$ can be obtained in the glassy state. Superconductivity was observed in all alloys of this series and several other properties were systematically studied. Since this initial work, a large number of metallic glasses based on the refractory metals molybdenum, ruthenium, tungsten, and rhenium have been found. Results of studies of these new materials are reported here.

The atomic scale structure of several of the new alloys has been studied in detail using $x$-ray diffraction methods. Complete results of this work are published in a separate report. ${ }^{7}$ The radial distribution function (RDF) was computed and compared to that obtained from "dense random packing of hard spheres" (DRPHS) models of amorphous structure. 4 The experimentally determined RDF's are in general agreement with those predicted by the models. Previous work has suggested that DRPHS models also give a good description of the atomic arrangements in other (TM) ${ }_{1-x} M_{x}$ glasses. ${ }^{5,6}$ Together these diffraction studies suggest a common structural basis for all (TM) $1-x M^{M}$ glasses. 
In spite of the success of DRPHS models in accounting for the general features of experimentally determined RDF's, there is much that remains unclear concerning the structure of metallic glasses. In the present article, results of a systematic study of a variety of physical properties of refractory metal glasses are presented. In particular, the variation of properties with metalloid content $x$ is investigated for alloys having a broad range of $x$ over which a glass is obtained. Based on these results, it is argued that (TM) $1-x M_{x}$ glasses are in many respects similar to intermetallic compounds. This analogy is developed by comparing the compositional variation of structure and properties to that observed for a crystalline intermetallic compound with extended homogeneity range.

Density measurements have been carried out for each alloy of this study. From the density, one can determine the mean atomic volume $\bar{V}$ for each alloy. Using a method recently proposed by Turnbul $7^{8}$, the effective volume of the metalloid constituent $\bar{V}_{M}$ can be estimated for each case. Owing to the extended range of $x$ over which several of these alloys form, it was possible to observe significant variation of both $\bar{V}$ and $\bar{V}_{M}$. Extrapolation to $x=0$ is found to yield useful information concerning $\vec{V}$ for the experimentally inaccessible "pure" amorphous TM matrix. The observed variation of $\bar{V}_{M}$ is explained in terms of an "excess volume" model where the "excess volume" of the glass is progressively reduced with increasing metalloid concentration $x$. Optimum space filling appears to be achieved near the observed upper limit of $x$ for which the glass can be formed. A particularly useful comparison can be made with interstitial compounds of the type first discussed by Hägg. ${ }^{9}$

The variation of the superconducting transition temperature $T_{c}$ and 
upper critical field gradient $\left[\mathrm{dH}_{\mathrm{c} 2} / \mathrm{dT}\right]_{T}=T_{\mathrm{C}}$ with metalloid species and content were investigated. For alloys of the form (Mo $\left.{ }_{6}{ }^{R u}{ }_{4}\right)_{1-x} x_{x}$ $(M=$ metalloid $), T_{c}$ decreases with $x$ in a roughly linear manner with a characteristic slope $\left[d T_{c} / d x\right]$ for each metalloid. The temperature and composition dependence of the electrical resistivity $\rho(T)$ and its temperature coefficient $\left[\frac{1}{\rho_{0}} \cdot \frac{\partial \rho}{\partial T}\right]\left(\rho_{0}=\right.$ residua $]$ resistivity at $10 \mathrm{w}$ temperature) have also been measured and are discussed.

The Vicker's hardness (VH) was measured for several glasses and found to increase with increasing metalloid content. The highest values $\left(1600-1800 \mathrm{~kg} / \mathrm{mm}^{2}\right)$ of $\mathrm{VH}$ were obtained for $\left(\mathrm{Mo}_{.6}{ }^{\mathrm{Ru}}{ }_{.4}\right){ }_{1-x^{\mathrm{B}} \mathrm{x}}$ and (Wu $\left.{ }_{.5}{ }^{R u}{ }_{.5}\right)_{1-x^{B} x}$ alloys. These values exceed those observed for other metallic glasses 10,11 and suggest that the elastic moduli and tensile strength of these refractory glasses are very high. Considerable ductility is observed for samples with low metalloid content. For

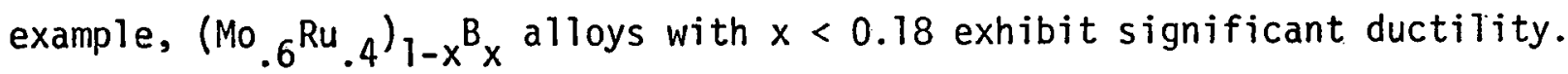
A decrease of ductility with increasing metalloid content is observed such that samples with $x>0.20$ are very prone to brittle fracture. This "ductile to brittle" transition as a function of metalloid concentration is shown to be common among glasses of the (TM) $1-x{ }^{M}$ family. Other investigators have observed embrittlement of (TM.) ${ }_{1-x} M_{x}$ glasses following low temperature annealing. 12,13 Both of these embrittlement effects can be discussed in terms of a "free volume" picture. The "excess volume" previously referred to is proposed as one component of the total free volume. Decreased "excess volume" results in embrittlement at high metalloid concentration.

The conclusions which may be drawn from the present data and analysis are presented and discussed in the final section of the paper. A 
description of the variation of physical and electronic properties with metalloid concentration is given based on an "ideal" structure concept. The analogy with crystalline intermetallic compounds is developed from this concept.

\section{EXPERIMENTAL PROCEDURES}

A complete list of the alloys used in this study is given in Table I. The samples were prepared by induction melting of the constituents on a silver boat under an argon atmosphere. For alloys containing volatile constituents, initial ingots were prepared by sintering powder compacts. The sintered compact is then melted as above. The ingots are checked for homogeneity after remelting several times, then broken into fragments which are used for melt quenching. The quenching is carried out using the "piston and anvil" technique described elsewhere. ${ }^{14}$ The final samples are in the form of foils having a thickness ranging from $40 \mu$ to $60 \mu$. Preliminary $x$-ray diffraction scans were taken on all foils using a Norelco scanning diffractometer with $\mathrm{Ni}$-filtered $\mathrm{Cu}-\mathrm{K} \alpha$ radiation. Samples judged to be amorphous on the basis of the initial scan were used for further study. Several samples of the $\left(\mathrm{Mo}_{0.6} \mathrm{Ru}_{0.4}\right)_{1-x} \mathrm{~B}_{\mathrm{x}}$ series were chemically thinned and examined with a Siemen's transmission electron microscope. Electron diffraction in the transmission mode was used to confirm the amorphous nature of the samples. The x-ray data used in computing the RDF's was obtained using a G.E. scanning goniometer with filtered Mo-Ko radiation. Secondary fluorescent contributions in alloys containing Mo were prohibitively large. Thus, the radial distribution functions were computed mainly for $W-R u$ base glasses. The details of the RDF calculation 
TABLE I. Alloy composition, superconducting transition temperature $T_{c}$, room temperature electrical resistivity $\rho_{0}$, and temperature coefficient of resistivity $\alpha$ (see text) for samples of this study.

\begin{tabular}{|c|c|c|c|c|}
\hline \multirow[b]{2}{*}{$\left(\mathrm{Mo}_{0 .} 6^{\mathrm{Ru}} 0.4_{1-x^{\mathrm{B}} \mathrm{x}}\right.$} & \multicolumn{2}{|c|}{$T_{c}(K)$} & $\rho_{0}(\mu \Omega \mathrm{cm})$ & \multirow[t]{2}{*}{$\alpha\left(10^{-4} K^{-1}\right)$} \\
\hline & & & & \\
\hline$x=0.10$ & $7.15=$ & 0.1 & $1.35 \pm 20$ & 0.0 \\
\hline 0.12 & 7.00 & $"$ & 120 & $-n .5$ \\
\hline 0.14 & 6.25 & $"$ & 120 & 0.0 \\
\hline 0.16 & 6.40 & $"$ & 125 & 0.0 \\
\hline 0.18 & 6.05 & $"$ & 150 & -1.2 \\
\hline 0.20 & 5.75 & $"$ & 205 & -5.3 \\
\hline 0.22 & 5.40 & $"$ & 220 & -5.9 \\
\hline 0.24 & 5.05 & $"$ & 255 & -6.0 \\
\hline \multicolumn{5}{|l|}{$\left(\mathrm{Mo}_{0.6^{R u_{0}}}\right)_{1-x^{S i}}$} \\
\hline$x=0.18$ & 5.40 & $"$ & $220 \pm 20$ & -3.4 \\
\hline 0.20 & 5.00 & " & 215 & -2.5 \\
\hline 0.22 & 4.75 & $"$ & 245 & -2.5 \\
\hline 0.24 & $4.45^{\circ}$ & $"$ & 230 & -2.6 \\
\hline 0.26 & 4.05 & $"$ & 205 & -2.4 \\
\hline 0.28 & 3.60 & $"$ & 230 & -3.0 \\
\hline 0.30 & 3.20 & $"$ & 210 & -2.1 \\
\hline 0.32 & 2.80 & " & - & \\
\hline \multicolumn{5}{|l|}{$\left(\mathrm{Mo}_{0.6}{ }^{\mathrm{Ru}} 0.4\right)_{1-x^{\mathrm{P}} \mathrm{x}}$} \\
\hline$x=0.16$ & 6.60 & & 200 & -0.5 \\
\hline 0.20 & 6.00 & & 280 & -1.4 \\
\hline \multicolumn{5}{|l|}{$\left(\mathrm{Mo}_{0.6}{ }^{\mathrm{Ru}} 0.4\right)_{1-x^{\mathrm{As}}}$} \\
\hline$x=0.24$ & 4.60 & & - & - \\
\hline 0.28 & 3.80 & & $\therefore$ & \\
\hline$\left(\mathrm{Mo}_{0.6}{ }^{\mathrm{Ru}} 0.4\right)_{0.6} \mathrm{Ge}_{0.33}$ & 1.60 & & 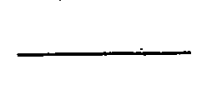 & L \\
\hline$\left(w_{0.5^{R u_{0}}} 0.5\right)_{0.80^{B}}{ }_{0.20}$ & 3.50 & & 295 & -1.0 \\
\hline$\left(w_{0.5}{ }^{R u_{0.5}}\right)_{0.80} \mathrm{P}_{0.20}$ & 4.55 & & 325 & -2.4 \\
\hline 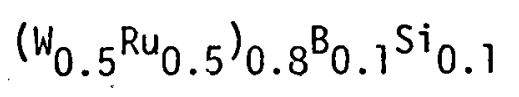 & 3.45 & & - & \\
\hline$\left(W_{0.5^{R u}} u_{0.5}\right)_{0.8^{B} 0.1^{A l_{0}} 0.1}$ & 3.95 & & & \\
\hline
\end{tabular}


are described in a separate report. ${ }^{7}$

The critical temperatures $\left(T_{c}\right)$ were measured both inductively and resistively. The $\mathrm{H}_{\mathrm{c} 2}$ data were obtained by making four-point resistance measurements with the samples situated in the core of a Nb-Ti superconducting solenoid. The direction of current flow was always normal to the field. The half-point of the resistive transition (superconductingnormal) was taken to define $\mathrm{H}_{\mathrm{c} 2}$. Absolute resistivity measurements were made at $77 \mathrm{~K}$ and room temperature on samples having well defined length and cross-sectional area. The density of each sample was measured using hydrostatic weighing with toluene as the working fluid. The error in these measurements is typically $0.5 \%$. Vicker's hardness tests were carried out using a Leitz micro-hardness tester (diamond pyramid technique) with a typical load of 500 grams. The large load was essential for obtaining an indentation sufficiently large for accurate reading. The present samples have unusually high hardness values. Care was taken to ensure that the indentation depth remains small by comparison to the sample thickness.

\section{RESULTS AND ANALYSIS}

\section{A. Structure}

A complete discussion of the results of the $x$-ray diffraction study will be published in a separate report which describes the calculation and analysis of the RDF for several alloys. ${ }^{7}$ These results substantiate the amorphous nature of the samples and show the atomic scale structure to be very' similar to that observed in previously studied $\mathrm{TM}_{1-\mathrm{x}} \mathrm{M}_{\mathrm{x}}$ glasses. ${ }^{5,6}$ An example of a typical RDF is shown in Fig. 1 for the alloy 


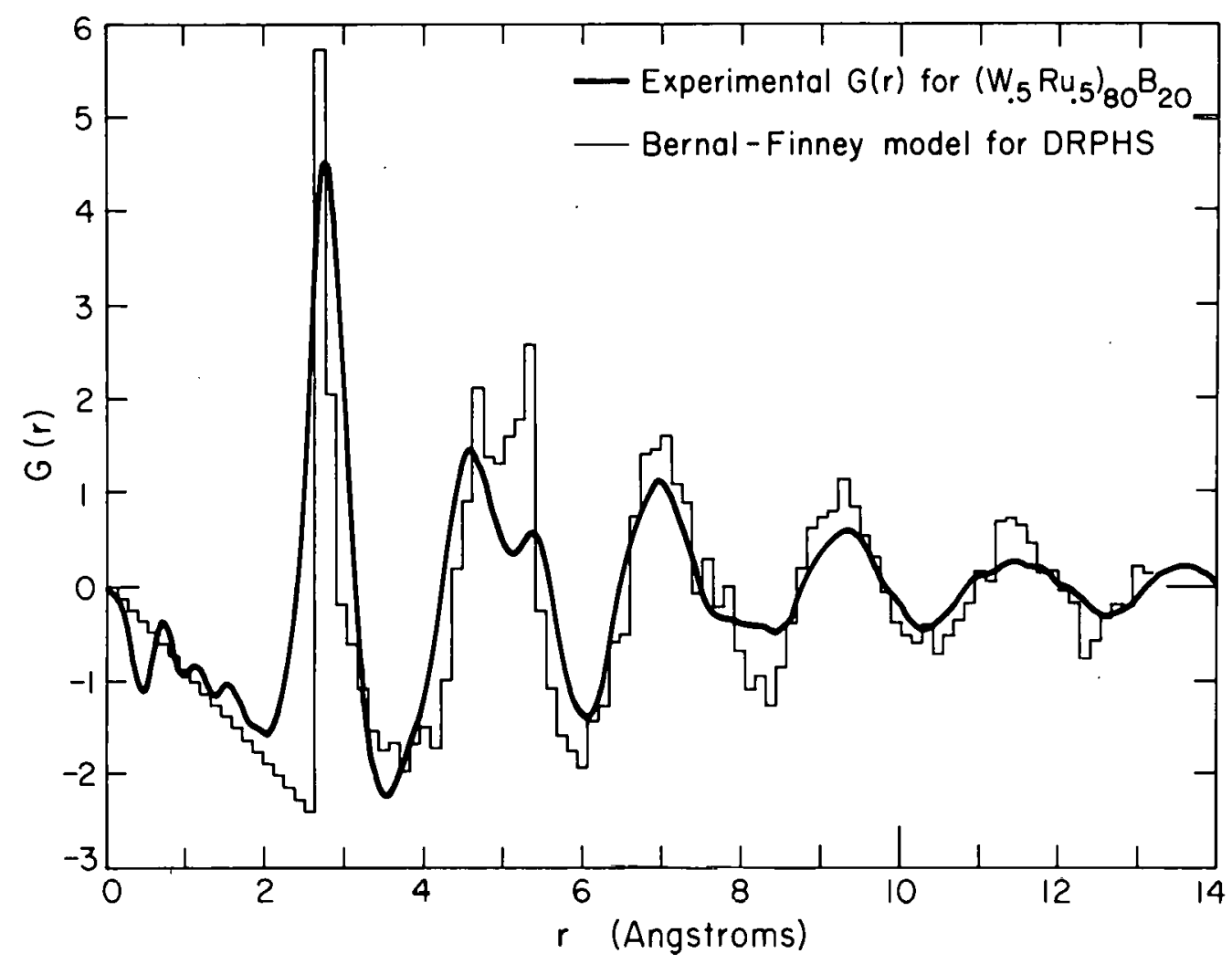

Fig. 1. The reduced radial distribution function $G(r)$ for amorphous

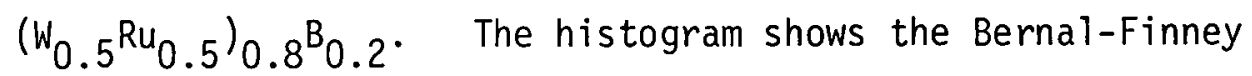
results for a DRPHS with sphere size chosen to best fit the data. 
$\left(W_{0.5^{R u}} 0.5^{2}\right)_{0.8^{B}} 0.2^{\circ}$. The function $G(r)$ is defined as

$$
G(r)=4 \pi r(\rho(r)-\bar{\rho})
$$

where $\rho(r)$ the density of atoms at a distance $r$ from a given atom and $\bar{\rho}$ is the average atomic density. For the ternary alloy, $\rho(r)$ is a weighted sum of contributions from various atomic species taken pairwise. ${ }^{7}$ The experimental $G(r)$ in Fig. $I$ is compared to that calculated by Finney ${ }^{4}$ for a DRPHS model of amorphous structure. For further details, the reader is referred to reference 7. All alloys for which the RDF has been computed show structural arrangements which are in general agreement with the DRPHS models.

Additional evidence for the amorphous nature of the samples is provided by transmission electron diffraction carried out on chemically thinned samples. Samples of $\left(\mathrm{Mo}_{0.6}{ }^{\mathrm{Ru}} \mathrm{u}_{0.4}\right)_{1-x^{\mathrm{B}} \mathrm{x}}$ series with $\mathrm{x}=0.12,0.16$, and 0.20 were studied in this manner. For $x=0.16$ and 0.20 no evidence of crystallization was found in samples judged to be amorphous on the basis of initial $x$-ray scans. The electron diffraction pattern is characterized by a series of diffuse bands very similar to those shown in reference 3 . For $x=0.12$, a small number of crystalline inclusions were found in some regions of the sample. These inclusions constituted roughly $1 \%$ of the sample.by volume. This sample did not show evidence of cyrstallization in initial $x$-ray scans. 


\section{B. Density and Atomic Volumes}

Measurements of density were carried out on most of the alloys of this study. Considerable information regarding the structure of the alloys can be deduced from these measurements. The mean atomic volume $\bar{V}$ of each amorphous alloy was first determined from its density and the average atomic weight. The volumes so determined are listed in Table II together with the densities and mean atomic weights.

The variation of mean atomic volume with metalloid concentration shown in Fig. 2 for the alloys (Mo $\left.{ }_{.6}{ }^{\mathrm{Ru}}{ }_{.4}\right)_{1-x^{\mathrm{B}} \mathrm{x}}$ and $\left(\mathrm{Mo}_{.}{ }^{\mathrm{Ru}}{ }_{.4}\right)_{1-x^{\mathrm{Si}} \mathrm{x}}$ is of particular interest since $x$ has a comparatively large range. This variation reflects the effective packing fraction of atoms and its variation with metalloid content. Turnbul $1^{8}$ has recently suggested a scheme for determining the effective partial atomic volume of metalloid elements in similar amorphous alloys of the metal-metalloid type. In this scheme, the mean atomic volume of the transition.. metal (or alloy) component is taken to be that obtained for a crystalline close-packed arrangement of the metal (or alloy) and is referred to as $V_{A}^{0}$. From the mean atomic volume $\bar{V}$ measured for the amorphous alloy, one can then calculate the mean volume occupied by metalloid atoms $\nabla_{B}$ straight forwardly. The result is

$$
\bar{v}_{B}=\left[\frac{\bar{v}-(1-x) v_{A}^{0}}{x}\right]
$$

where $x$ is the metalloid content in an alloy of the general form (TM) $1-x M_{x}$. This scheme was employed in the present case to determine the effective metalloid volume $\bar{V}_{B}$ for the alloys. The value of $V_{A}^{0}$ was determined using data ${ }^{15}$ for the lattice parameter of the hcp solid solution of Mo and Ru extrapolated to the composition Mo ${ }_{6}{ }^{\mathrm{Ru}}{ }_{.4}$. The 
TABLE II. Density, average atomic weight, and average atomic volume $\bar{v}$ for alloys of this study. Data are averaged over two samples for most compositions.

\begin{tabular}{|c|c|c|c|}
\hline Alloy & Density $(\mathrm{g} / \mathrm{cc})$ & $\begin{array}{l}\text { Average } \\
\text { Atomic Weight }\end{array}$ & $\bar{v}\left(\AA^{3}\right)$ \\
\hline \multicolumn{4}{|l|}{$\left(\mathrm{Mo}_{0.6}{ }^{\mathrm{Ru}} \mathrm{u}_{0.4}\right)_{1-x^{\mathrm{B}} \mathrm{x}}$} \\
\hline$x=0.10$ & $10.49 \pm 0.05$ & 89.27 & 14.14 \\
\hline 0.12 & 10.48 & 87.53 & 13.87 \\
\hline 0.14 & 10.28 & 85.79 & 13.86 \\
\hline 0.16 & 10.33 & 84.04 & 13.52 \\
\hline 0.18 & 10.19 & 82.30 & 13.42 \\
\hline 0.20 & 10.15 & 80.56 & 13.18 \\
\hline 0.22 & 10.33 & 78.81 & 12.68 \\
\hline 0.24 & $10.14 \quad "$ & 77.07 & 12.63 \\
\hline \multicolumn{4}{|l|}{$\left(\mathrm{Mo}_{0.6^{\mathrm{Ru}}} 0.4^{)_{1-x}} \mathrm{Si}_{\mathrm{x}}\right.$} \\
\hline$x=0.18$ & $9.79 \pm 0.05$ & 85.42 & 14.50 \\
\hline 0.20 & $9.67^{-} "$ & 84.02 & 14.43 \\
\hline 0.22 & 9.56 & 82.62 & 14.35 \\
\hline 0.24 & 9.45 & 81.22 & 14.27 \\
\hline 0.26 & 9.26 & 79.83 & 14.37 \\
\hline 0.28 & 9.15 & 78.42 & 14.23 \\
\hline 0.30 & 9.19 & 77.03 & 13.92 \\
\hline 0.32 & 9.07 & 75.63 & 13.85 \\
\hline \multicolumn{4}{|l|}{$\left(\mathrm{Mo}_{0.6}{ }^{\mathrm{Ru}} 0 .{ }\right)_{1-x^{\mathrm{P}}}$} \\
\hline$x=0.16$ & $10.15 \pm 0.05$ & 87.27 & 14.28 \\
\hline 0.20 & $9.88 \quad "$ & 84.59 & 14.22 \\
\hline$\left.\left(w_{0.5}{ }^{R u_{0}} 0.\right)\right)_{0.8^{P_{0}}} 0.2$ & $13.94 \pm 0.05$ & 120.16 & 14.32 \\
\hline$\left.\left(W_{0.5}{ }^{R u_{0}} 0.\right)\right)_{0.8^{B}} 0.2$ & $14.65 \pm 0.05$ & 116.13 & 13.17 \\
\hline
\end{tabular}




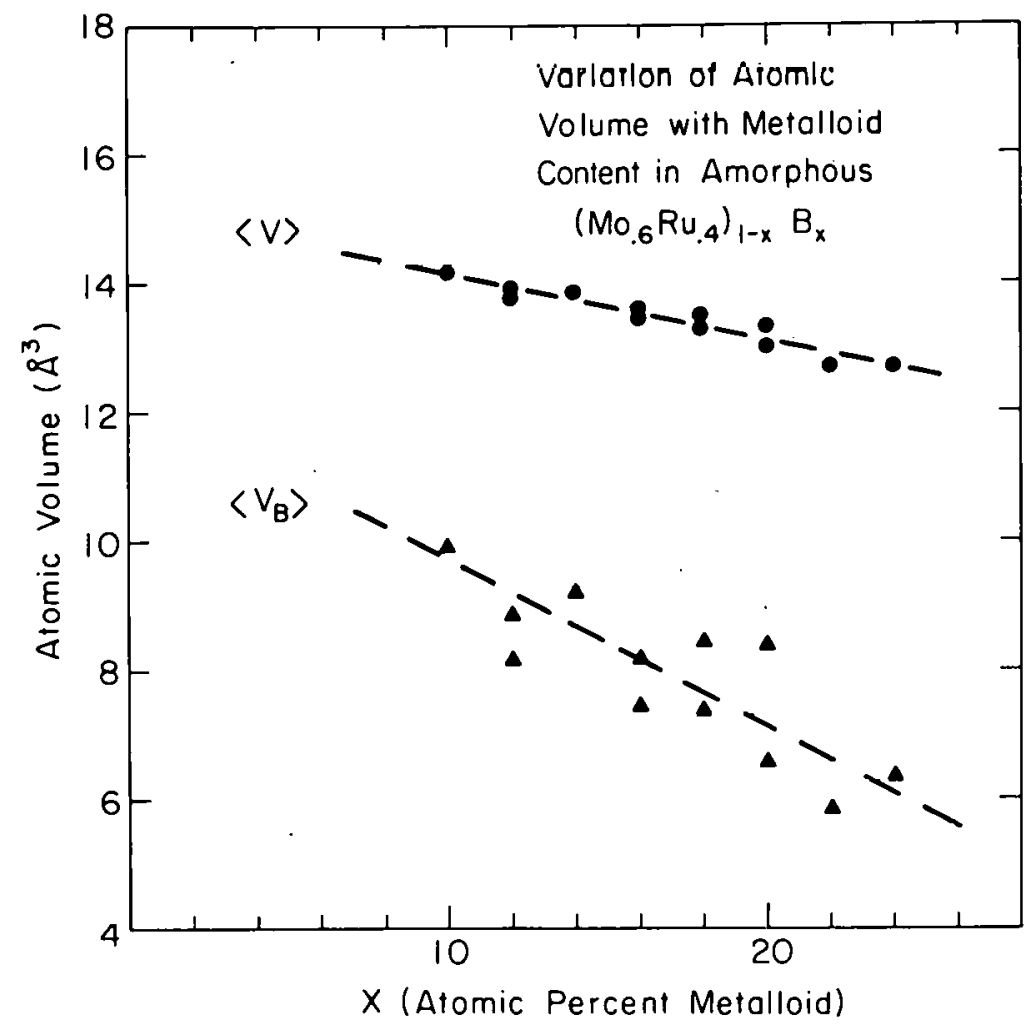

Fig. 2. The variation of mean atomic volume $\bar{V}$ and effective boron volume $\bar{V}_{B}$ with boron concentration for $\left(\mathrm{Mo}_{0.6}{ }^{\mathrm{Ru}} 0.4\right)_{7-x^{B}}{ }$ alloys. Eqn. (2) was used to determine $\bar{V}_{B}$. 
actual value of $V_{A}^{0}$ used was $14.61 \AA^{3}$. The results for $\bar{V}_{B}$ are shown in Fig. 2 and Fig. 3 along with the variation of $\bar{V}$ for (Mo $\left.{ }_{.6}{ }^{R u}{ }_{.4}\right)_{1-x} x_{x}$ and (Mo $\left..6^{R u} .4\right)_{1-x} S_{x}$. The data for $\bar{V}$ can be seen to vary in a linear manner with $x$ as is frequently found in crystalline phases with extended homogeneity range. Both sets of data for $\bar{V}$ vs. $x$ were fitted to a straight line using a least squares fit. The following expressions obtained described the experimental variation of $\bar{V}$.

$$
\begin{aligned}
& \bar{V}=15.34-11.40 \times\left(\AA^{3}\right) \\
& \bar{V}=15.32-4.36 \times\left(\AA^{3}\right)
\end{aligned}
$$

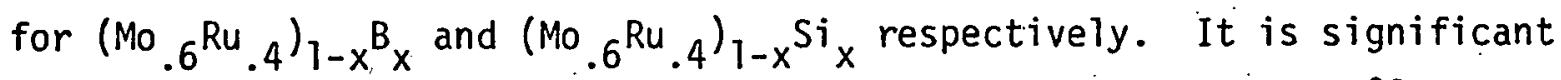
that both sets of data imply an extrapolated value of $\bar{v}_{0} \approx 15.3 \AA^{3}$ in the limit where $x+0$, i.e. for amorphous (Mo ${ }_{.6}$ Ru .4 ) containing no metalloid additions. Since hcp Mo.$_{6}^{\text {Ru }}{ }_{.4}$ has a mean atomic volume $v_{A}^{0}=14.61\left(\AA^{3}\right)$, we can estimate the volume change of the "pure" metal alloy on going from the crystalline close-packed to amorphous phase. The relative volume change $\left[\frac{\bar{V}_{0}-V_{A}^{0}}{V_{A}^{0}}\right]$ is found to be $5.0 \%$. This is somewhat larger than the the typical volume change (1-2\%) observed upon fusion of close packed metals. However, it should be recalled that the value of $v_{A}^{0}$ used here was determined from room temperature data for the lattice parameter. Near the melting point of hcp Mo ${ }_{6}{ }^{\mathrm{Ru}} .4, \mathrm{v}_{\mathrm{A}}^{0}$ will be somewhat larger owing to the effect of thermal expansion. The amorphous alloys of this study are rapidly quenched from the liquid state and probably retain a free volume characteristic of a high "fictive temperature". The $5.0 \%$ volume change must reflect in part the difference between the high "fictive 


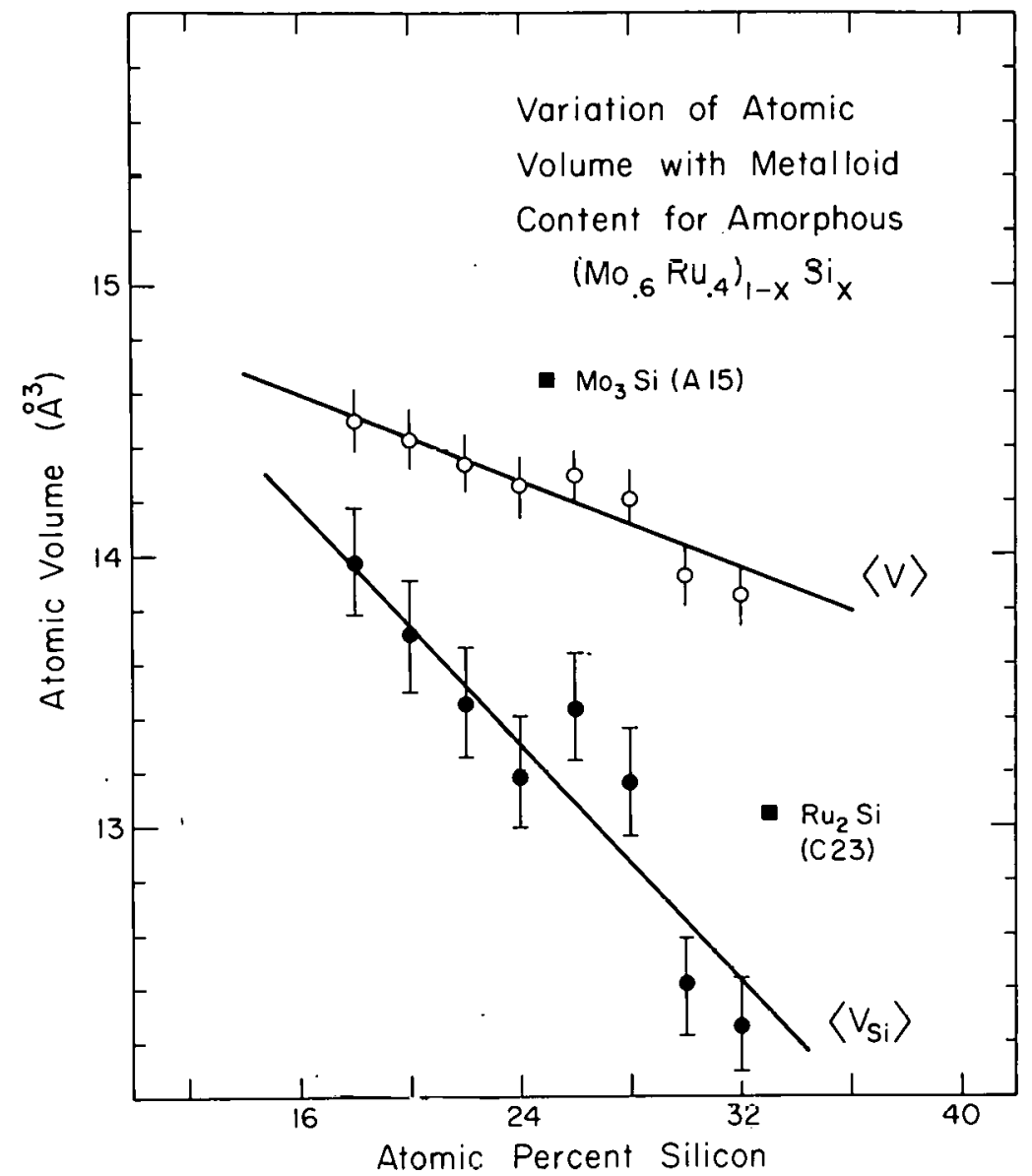

Fig. 3. The variation of mean atomic volume $\bar{V}$ and effective silicon volume $\bar{V}_{S i}$ with silicon concentration for $\left(\mathrm{Mo}_{0.6} \mathrm{Ru}_{0.4}\right)_{1-x} \mathrm{Si} x$ alloy. Eqn. (2) was used to determine $\bar{V}_{S i}$. 
temperature" of the amorphous alloy and room temperature where $V_{A}^{0}$ is determined.

The validity of the above analysis might be questioned since it was assumed that the value of $\bar{V}_{0}$ for amorphous (Mo.$^{R u}{ }_{.4}$ ) could be obtained by linear extrapolation of the experimental data. However, the excellent agreement between the two values $15.32\left(\AA^{3}\right)$ and $15.34\left(\AA^{3}\right)$ obtained from data on (Mo $\left.{ }_{.6}{ }^{\mathrm{Ru}}{ }_{.4}\right)_{1-x^{\mathrm{B}} x}$ and (Mo $\left.{ }_{.6}{ }^{\mathrm{Ru}}{ }_{.4}\right)_{1-x} \mathrm{Si}_{x}$ is rather reassuring. In order to establish the validity of this procedure more generally, it was applied to several other previously studied amorphous alloys. The density of a series of $\left(\mathrm{Pd}_{.6} \mathrm{Cu}{ }_{.4}\right)_{1-x} \mathrm{P}_{x}$ amorphous alloys ${ }^{16}$ was measured and analyzed according to the above procedure. For these alloys, $x$ ranges from 0.15 to 0.25 . The data are listed in Table III. From the lattice parameter of the fcc solid solution $\left(\mathrm{Pd}_{.6} \mathrm{Cu}{ }_{.4}\right)^{15}$, a value of $v_{A}^{0}=13.62\left(\AA^{3}\right)$ is obtained. A least squares fit to the data for $\nabla$ vs. $x$ yields an expression

$$
\bar{V}=14.33-2.57 \times\left(\AA^{3}\right)
$$

Again the relative volume change of $\mathrm{Pd}_{.6} \mathrm{Cu}{ }_{4}$ on going from the crystalline close packed to the amorphous phase can be estimated. In this case

$$
\left[\frac{V_{0}-V_{A}^{0}}{V_{A}^{0}}\right] \text { is found to be } 5.2 \% \text {. }
$$

As a final test, the density data ${ }^{17}$ for a series of $\operatorname{La}_{1-x}{ }^{G a} x$ a 1 loys was analyzed. Here, Ga plays the role of a metalloid atom. The data are again listed in Table IV. Here, the value of $x$ ranges from 0.16 to 0.28 . Using a least squares fit one finds that the expression

$$
\bar{V}=39.20-28.73 \times\left(\AA^{3}\right)
$$


TABLE III. Density and average atomic volumes of $\left(P d .6^{C u}{ }_{.4}\right){ }_{1-x} P x$ and ${ }_{\text {La }}{ }_{1-x} \mathrm{Ga}_{x}$ alloys. Density data for $\mathrm{La}_{1-x} \mathrm{Ga}_{x}$ were taken from reference 17. Calculated values of $\bar{V}_{B}$ are also given (see text).

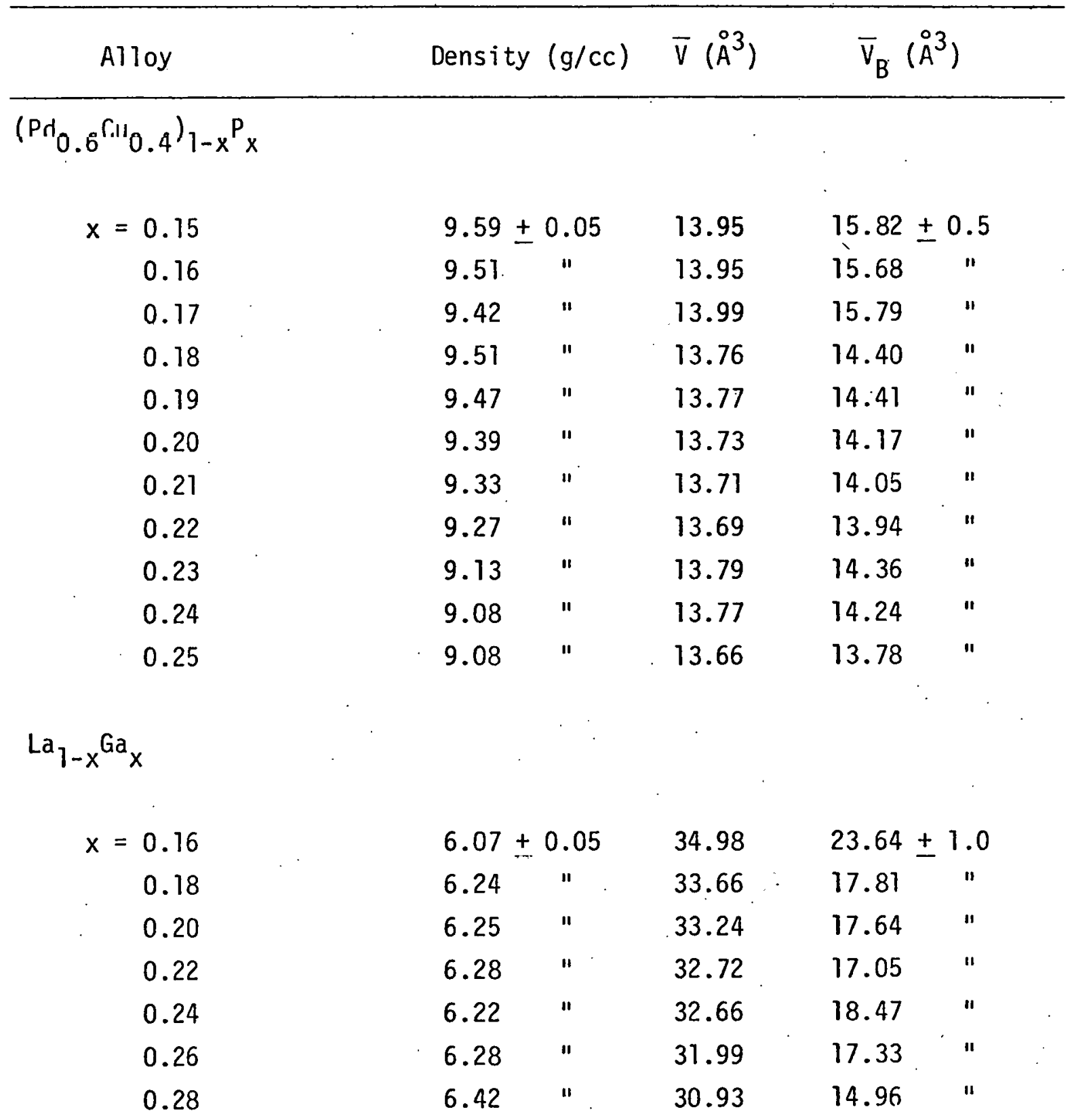


Again, the relative volume change for the hcp $\alpha$-La to amorphous La transition can be estimated. It is found that $\left[\frac{v_{0}-v_{A}^{0}}{v_{A}^{0}}\right]=4.8 \%$ where $v_{A}^{0}=37.42\left(\AA^{3}\right)$ for the close packed form.

Summarizing, from data on amorphous alloys of the form (TM) $1-x{ }^{M} x$, the average atomic volume $\bar{v}_{0}$ for each "amorphous TM" is extrapolated and compared to that of crystalline close-packed TM. The relative volume change $\left[\frac{V-V_{A}^{0}}{V_{A}^{0}}\right]$ is $5.0 \pm 0.2 \%$ in all cases examined. This volume change is apparently characteristic of the crystalline close packed to amorphous transitions in close-packed metals and alloys which form closepacked solid solutions. At this point one can compute the packing fraction for the "pure" amorphous metals and alloys. For crystalline close packing, the packing fraction $n_{c p}=0.7405$ and is defined as the fraction of space filled by close-packed hard spheres in contact. For "pure" amorphous alloys (i.e. containing no metalloids), the packing fraction is given by $n_{A}^{0}=n_{C p}\left[V_{A}^{0} / \bar{V}_{0}\right]=0.705 \pm 0.0015$ for a 11 cases examined here. Previous estimates of the packing fraction for amorphous alloys give values of $n$ ranging from 0.66 to 0.69 . However these estimates were all made for alloys containing metalloids by making the rather arbitrary assumption that the hard sphere volume of metalloid atoms is determined by its covalent radius. The present analysis avoids this problem by extrapolating the packing fraction for $(T M)_{1-x}{ }^{M} x$ alloys in the limit where $x \rightarrow 0$. In this limit $\eta$ is well defined and independent of assumptions concerning the metalloid volume. It is in this limit, in fact, that a comparison with DRPHS models of amorphous structure which use a single size sphere is most meaningfur. The packing fraction $n_{A}^{0}=0.705 \pm 0.0015$ is 
substantially larger than that of mechanical single size sphere DRPHS models. ${ }^{6}$ Computer generated relaxed DRPHS models also do not yield packing fractions this large. 18,19

We now turn to the variation of metalloid volume $\bar{V}_{B}$ with $x$. This variation is shown in Figs. 2 and 3 for $\left(M_{0} \cdot 6^{R u} \cdot{ }_{4}\right){ }_{1-x} B_{x}$ and (Mo $.6^{\mathrm{Ru}} .4^{\text {) }}{ }_{1-\mathrm{x}} \mathrm{Si}_{\mathrm{x}}$. In both cases $\bar{V}_{B}$ is found to decrease rapidly with increasing $x$ over the range of amorphous phase formation. The procedure used in computing $\bar{V}_{B}$ amounts to assigning all volume not accounted for by TM atoms (using the close-packed TM volume) to $M$ atoms. In order to interpret the variation of $\bar{V}_{B}$ with $x$, one needs to have some idea of the hard sphere volume of an $M$ atom. The covalent radius of boron is $r_{\text {cov. }}=0.82 \AA$ and the metallic radius is $r_{M}=0.98 \AA$. These radii give hard sphere volumes of $2.31\left(\AA^{3}\right)$ and $3.94\left(\AA^{3}\right)$ respectively. From the metallic hard sphere volume, one can deduce the effective volume for boron in a close-packed metallic arrangement to be $\eta_{c p}^{-1}(3.94)\left(\AA^{3}\right)=5.32\left(\AA^{3}\right)$. Another estimate of the effective volume of boron is obtained from data for the crystalline borides $\mathrm{Mo}_{2} \mathrm{~B}$ and $\mathrm{Ru}_{7} \mathrm{~B}_{3}$. Using $\mathrm{V}_{\mathrm{A}}^{0}$ appropriate to crystalline closed packed Mo, and Ru (determined from metallic radii), eqn. (1), and $\bar{V}$ determined from crystallographic data ${ }^{15}$, one obtains $5.98\left(\AA^{3}\right)$, and $6.15\left(\AA^{3}\right)$ repsectively for the effective volume of boron in $\mathrm{Mo}_{2} \mathrm{~B}$ and $\mathrm{Ru}_{7} \mathrm{~B}_{3}$. The above considerations suggest an effective boron volume of 5-6 $\left(\AA^{3}\right)$. The data in Fig. 2 show $\bar{V}_{B} \simeq 5-6\left(\AA^{3}\right)$ for $x \approx 0.24$. This value of $x$ is near the upper limit of $x$ for which an amorphous phase can be obtained. For $x<0.24, \bar{V}_{B}$ is larger, increasing with decreasing $x$ to $\bar{V}_{B} \sim 10\left(\AA^{3}\right)$ at $x=0.10$. The latter value of $\bar{V}_{B}$ is clearly much larger than one expects for a boron atom. The interpretation of this large volume becomes clear if we now recall that $\bar{V}_{0}$ exceeds $V_{A}^{0}$ by $5.0 \%$. This 
"excess volume" must be accounted for in determining $\bar{V}_{B}$. ' In fact, for dilute boron concentrations, it is clear that $\bar{V}_{B}$ computed using eqn. (1) would diverge as $x \rightarrow 0$. Polk $k^{20,21}$ has suggested a model of amorphous ( $\mathrm{TM})_{1-x} \mathrm{M}_{x}$ alloys in which $M$ atoms fill the interstitial holes (Bernal holes ${ }^{3}$ ) in a DRPHS TM matrix. The above results seem to substantiate this picture. The large values of $\bar{V}_{B}$ observed at low $x$ for (Mo.$\left._{6}{ }^{R u}{ }_{4}\right)_{1-x^{B}} x$ suggest the presence of unfilled interstial volume or "excess volume". According to the Polk picture, complete occupancy of Bernal holes should occur for $x \sim 0.20-0.23$. It is of further interest to note that the atomic environment of boron in crystalline $\mathrm{Mo}_{2} \mathrm{~B}$ and $\mathrm{Ru}_{7} \mathrm{~B}_{3}$ consists of 8 first neighbor Mo (Ru) atoms arranged in a manner nearly identical to that of the tetragonal dodecahedral hole ${ }^{3}$ described by Bernal. Summarizing, it has been shown that the excess volume of amorphous Mo ${ }_{6}{ }^{\mathrm{Ru}}{ }_{4} 4$ defined by $\left[\bar{V}_{0}-V_{A}^{0}\right]$ is progressively filled by boron addition with complete filling occurring somewhere near the upper limit of boron concentrations for which an amorphous phase can be obtained by liquid quenching.

The same analysis can be applied to the case of $\left(\mathrm{Mo}_{.6}{ }^{\mathrm{Ru}} \cdot{ }_{4}\right)_{1-x} \mathrm{Si}_{\mathrm{x}}$ alloys. The variation of $\bar{V}_{S i}$ with $x$ is shown in Fig. 3 . Again it is observed that $\bar{V}_{S i}$ decreases rapidly with increasing $x$ over the measured range of data. An estimate of the effective volume of silicon can again be obtained from independent considerations. The metallic radius of silicon is $r_{M}=1.32 \AA$. This gives a hard sphere volume of $9.63\left(\AA^{3}\right)$ and an effective close-packed volume of $n_{c p}^{-1}(9.63)\left(\AA^{3}\right)=13.01 \AA^{3}$. From data on the crystalline silicides $\mathrm{Mo}_{3} \mathrm{Si}$ and $\mathrm{Ru}_{2} \mathrm{Si}$ one finds $\bar{V}_{\mathrm{Si}}=12.88\left(\AA^{3}\right)$ and $\bar{V}_{S i}=11.90\left(\AA^{3}\right)$ respectively following the same procedure used previously for crystalline borides. Summarizing, one expects an effective silicon volume $\bar{V}_{S i} \sim 12-13\left(\AA^{3}\right)$ from these considerations. Again we find 
that $\bar{V}_{S i}$ exhibits the expected volume near the upper limit of $x$ for which an amorphous phase forms. From Fig. $3, \bar{V}_{S i} \sim 12-13\left(\AA^{3}\right)$ for $x \sim 0.28-0.32$. In analogy with the (Mo $\left.{ }_{.6}{ }^{R u}{ }_{.4}\right) 1-x^{B} x$ system, it can be argued that the "excess volume" of the amorphous (Mo ${ }_{.6}{ }^{\mathrm{Ru}}{ }_{.4}$ ) matrix is filled for $x$ near the upper limit of the amorphous phase field. In contrast to the case of boron, the Polk picture does not seem so attractive for explaining the filling of excess volume in this case. Two observations contradict the Polk model. First optimum filling of "excess volume" occurs at a higher metalloid concentration than in the Polk picture, and second, the large metallic radius of silicon would require a considerable dilation of the Bernal holes in order to accommodate the atom. The latter has previously been cited ${ }^{6}$ as evidence against the Polk model for other amorphous alloys.

Finally, a few comments should be made concerning the variation of $\bar{V}_{B}$ for the cases of $\mathrm{La}_{1-x^{G a}}$ and $\left({ }^{\mathrm{Pd}}{ }_{.6}{ }^{\mathrm{Cu}}{ }_{.4}\right)_{1-x} \mathrm{P}_{x}$ previously mentioned. The behavior of $\bar{V}_{G a}$ as determined by eqn. (1) can be seen from the data in Table III. At $x=0.16 \bar{V}_{G a} \cong 24\left(\AA^{3}\right)$ decreasing to $\bar{V}_{G a} \cong 15\left(\AA^{3}\right)$ at $x=0.28$. The close-packed volume of gallium calculated from its metallic radius $r_{M}=1.41 \AA$ is $15.9\left(\AA^{3}\right)$. Again, there appears to be an "excess. volume" which decreases with $x$ to a near zero value for $x$ near the upper limit of the amoprhous phase field. A similar result is found for (Pd. $\left.{ }^{\mathrm{Cu}}{ }_{.4}\right)_{1-\mathrm{x}^{\mathrm{P}} \mathrm{x}}$. Thus, the existence of "excess volume" which decreases with increasing metalloid content appears to be a universal feature of metallic glasses of the form (TM) $1-x M_{x}$. This "excess volume" is observed to vanish for $x$ near the upper limit of the amorphous phase range.

In section IV of the paper, the concept of an ideal amorphous structure will be introduced. The "excess volume" described above can 
then be interpreted as a defect in the amorphous structure which plays a role similar to that of a vacancy in a crystal. A non-stoichiometric metallic glass containing a deficiency of metalloid atoms accomodates this deficiency through a structure characterized by "excess volume:" in the same manner that non-stoichiometry in many intermetallic compounds is accomodated by vacancy formation. A close analogy exists between metallic glasses and interstitial compounds such as those first described by Hägg. ${ }^{9}$

\section{Superconductivity and Electronic Properties}

The alloys studied were all found to be superconducting. The transition temperatures are listed in Table $I$ along with the gradient of the upper critical field $\left[\mathrm{dH}_{\mathrm{c} 2} / \mathrm{dT}\right]_{T_{c}}$ for each alloy. The upper critical field was in all cases found to closely follow a linear temperature dependence over the measured range of fields and temperature. Examples of $\mathrm{H}_{\mathrm{c} 2}(T)$ for the alloys of this type are given elsewhere. ${ }^{3,22}$ The linear behavior of $\mathrm{H}_{\mathrm{c} 2}(T)$ has been discussed and compared with theoretical predictions for other amorphous alloys in a prior publication. ${ }^{22}$ The field gradient is rather large for the present alloys ranging from 20-35 (k0e/K).

It is particularly interesting to consider the variation of $T_{c}$ and $\left[\mathrm{dH}_{\mathrm{c} 2} / \mathrm{dT}\right]_{\mathrm{T}_{\mathrm{C}}}$ with metalloid species and concentration. This variation was determined in detail for alloys of the form (Mo $\left.{ }_{.6}{ }^{R u}{ }_{.4}\right)_{7-x} M_{x}$. The dependence of $T_{c}$ on $x$ for various metalloids is shown in Fig. 4. The range of $x$ for which a glass is obtained varies substantially with the metalloid used. In the case of boron and silicon, the ranges are rather extended and given by $(0.10 \leq x \leq 0.24)$ and $(0.18 \leq x \leq 0.32)$ respectively. For the metalloids phosphorus, germanium, and arsenic, narrower concentration 


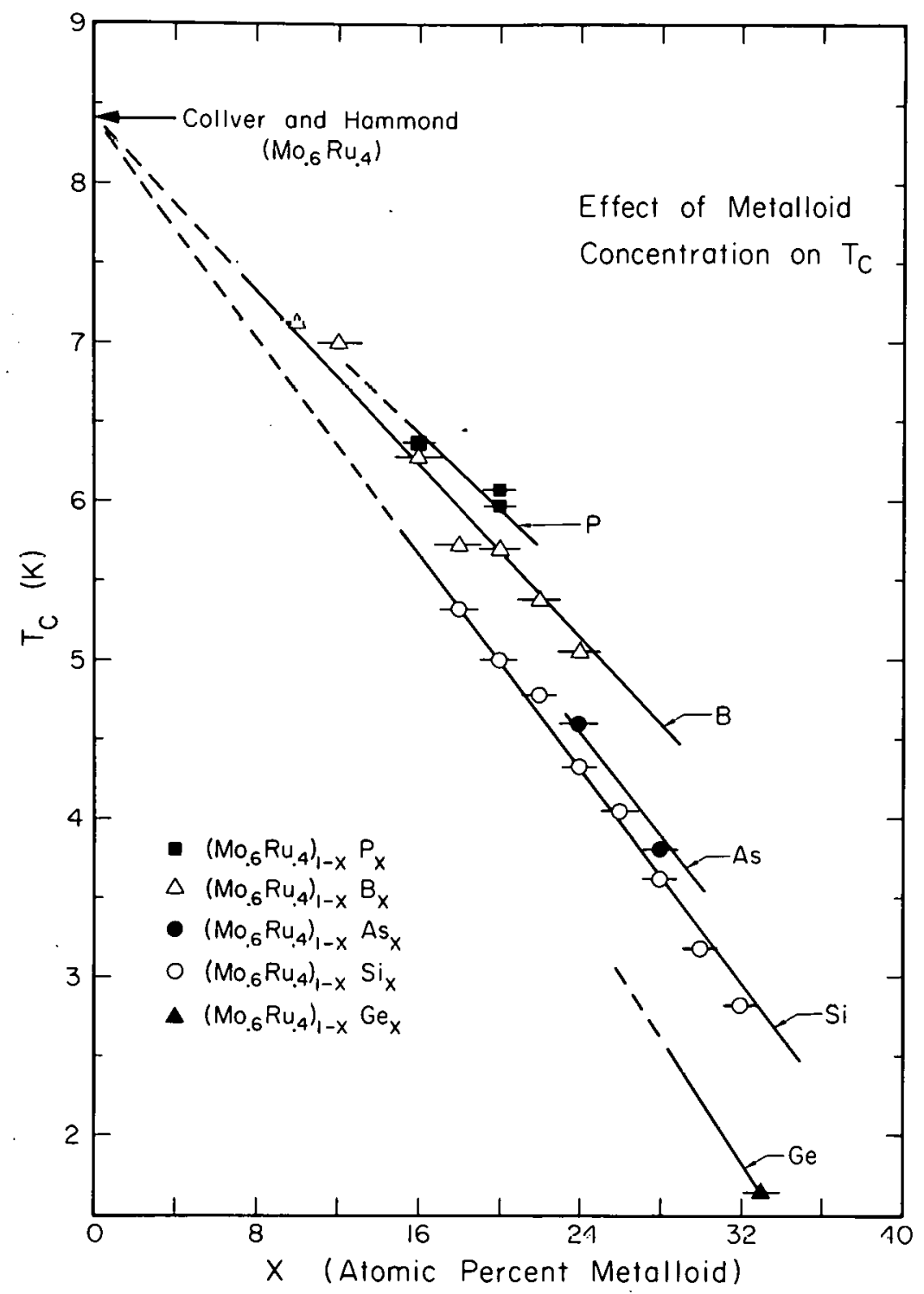

Fig. 4. Superconducting transition temperature as a function of metalloid concentration for $\left(\mathrm{Mo}_{0.6}{ }^{\mathrm{Ru}} 0.4\right)_{1-x} \mathrm{M}_{x}$ alloys. 
ranges $(0.16 \leq x \leq 0.20),(0.32<x<0.35)$, and $(0.20 \leq x \leq 0.28$ are observed. In all cases, $T_{c}$ decreases with increasing $x$ in a roughly linear manner. From the data for boron and silicon where the range of $x$ is extensive, it was possible to estimate the $T_{c}$ of glassy Mo ${ }_{6}{ }^{R u}{ }_{.4}$ by extrapolation. Using a least squares fit, this extrapolated $T_{c}$ is found to be $8.5 \pm 0.2(K)$ and is in very good agreement with the value $(\sim 8.5 \mathrm{~K})$ observed for amorphous Mo ${ }_{.6}{ }^{\mathrm{Ru}}{ }_{.4}$ films obtained using the cryoquench technique by Collver and Hammond. ${ }^{23}$ This result can be taken to indicate that the method of preparation does not appreciably influence the superconducting properties of these amorphous alloys. It indirectly. suggests a common atomic-scale structure for the cryoquenched films containing no metalloids and metallic glasses. It lends further credibility to the extrapolation of $\bar{V}$ for amorphous (Mo ${ }_{.6}{ }^{\mathrm{Ru}}{ }_{.4}$ ) from density data as discussed in the previous section.

Concerning the depression of $T_{c}$ by metalloid additions, the following observations can be made. For isoelectronic metalloids (i.e. silicon and germanium, or phosphorus and arsenic), $T_{c}$ is depressed more rapidly by the larger metalloid with higher atomic number. For metalloids which belong to the same period in the periodic table (i.e. aluminum, silicon; phosphorus, germanium, arsenic), the $T_{c}$ is depressed least for the metalloid having the largest valence and highest electronegativity. Similar observations can be made from the data of Meyer ${ }^{24}$ for ion implanted Mo films. The maximum $T_{c}$ observed by implantation of various metalloids into molybdenum films at low temperature follows the same trends found above although the non-uniform distribution of the implanted species makes a detailed comparison difficult. This suggests that an amorphous phase is formed by ion implantation although no direct structural evidence was presented in the work of Meyer. 
The variation of $\left[\mathrm{dH}_{\mathrm{c} 2} / \mathrm{dT}\right]$ with metalloid concentration is shown in Fig. 5. for the cases of boron and silicon. For (Mo.$\left.^{\mathrm{Ru}}{ }_{.4}\right)_{1-x^{B} x}$, the field gradient does not vary with $x$ to within experimental uncertainty. On the other hand, the field gradient increases rapidly with $x$ for amorhous (Mo.$\left.^{\mathrm{Ru}}{ }_{.4}\right)_{1-\mathrm{x}} \mathrm{Si} x$. In the limit $\mathrm{T} \rightarrow \mathrm{T}_{\mathrm{c}}, \mathrm{dH}_{\mathrm{c} 2} / \mathrm{dT}$ is given by 25

$$
\left[\mathrm{dH}_{\mathrm{c} 2} / \mathrm{dT}\right]_{T_{c}}=\frac{4 \mathrm{~K}_{\mathrm{B}} \mathrm{c}}{\pi \mathrm{e} D}
$$

One can thus determine the average electronic diffusivity $D=1 / 3 v_{F} l_{0}$ of electrons which participate in superconductive pairing. In this expression, $v_{F}$ is the average group velocity of electrons at the Fermi surface and $\ell_{0}$ is the average electron mean free path. The product $\left(v_{F} \ell_{0}\right)$ is apparently independent of $x$ in $\left(M_{0} \cdot 6^{R u}{ }_{.4}\right)_{1-x^{B} x}$ but decreases rapidly with $x$ in (Mo $\left.{ }_{6}{ }^{\mathrm{Ru}} .4\right)_{1-x} \mathrm{Si}_{x}$.

The electrical resistivity $\rho_{0}(T)$ of the alloys was found to decrease slightly with increasing temperature in nearly all cases. Examples of these data are shown in Fig. 6. Several theoretical models have been proposed to account for this behavior. ${ }^{26}$ The absolute value of $\rho_{0}$ at room temperature, $T_{r} \approx 295 \mathrm{~K}$, and $77 \mathrm{~K}$ (sample immersed in liquid nitrogen) are given in Table I for all alloys. The temperature coefficient of the resistivity averaged from $T=77 \mathrm{~K}$ to $T_{r}$ is defined by

$$
\alpha=\rho_{0}^{-1}(295)\left[\frac{\rho_{0}(295)-\rho_{0}(77)}{295-77}\right] \text {. }
$$

Values of this parameter are also in the Table. The variation of $\rho_{0}$ with metalloid concentration is illustrated in Fig. 7 for the (Mo $\left.{ }_{6}{ }^{R u}{ }_{.4}\right) 1-x^{B} x$ and (Mo.$\left.^{R u}{ }_{.4}\right)_{1-x} S_{x}$ alloy series. For the case of $\mathrm{Si}, \rho_{0}(295)$ is 


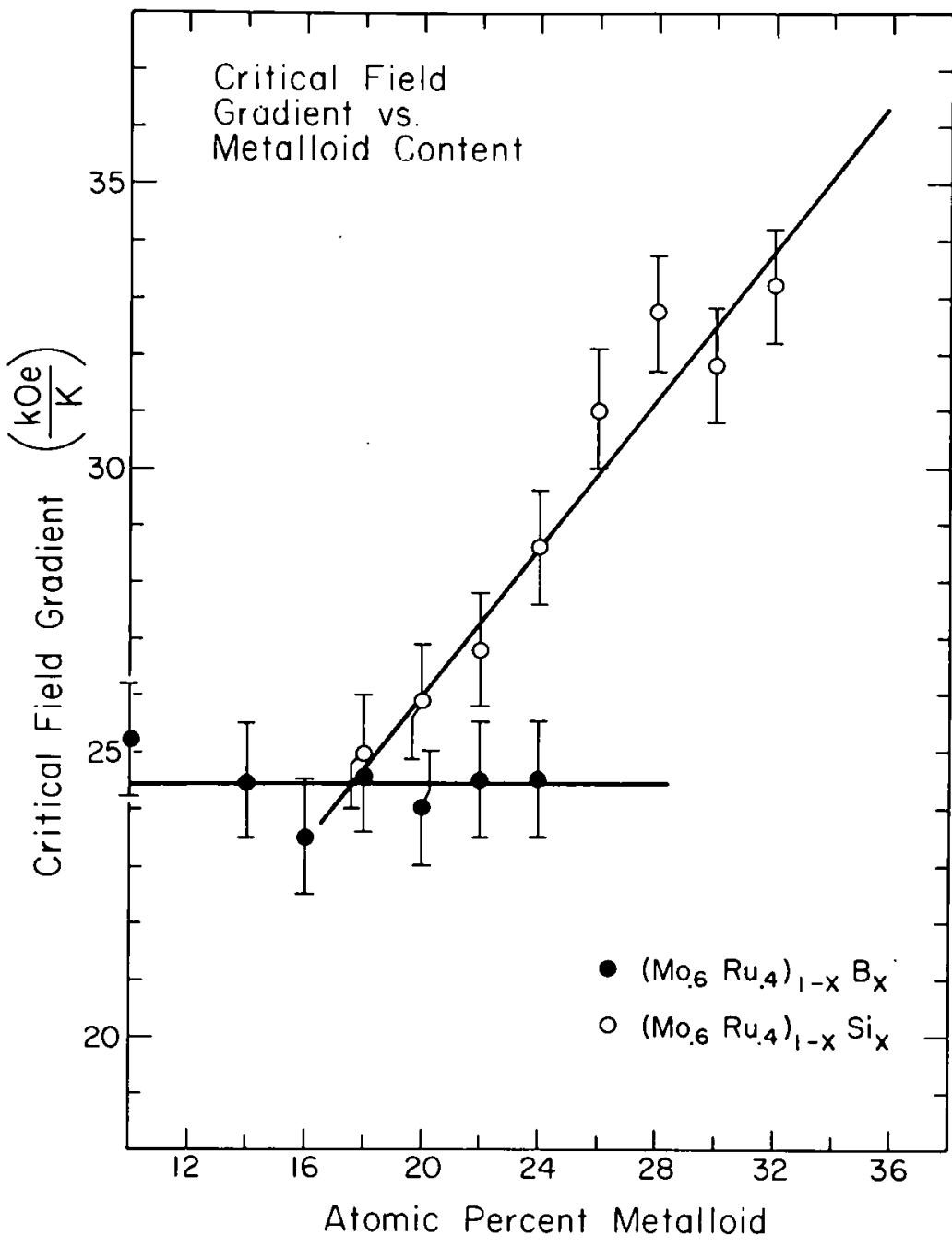

Fig. 5. Critical field gradient as a function of metalloid concentration for $\left(M_{0.6}{ }^{R u_{0}} 0.4\right)_{1-x} M_{x}$ alloys. 


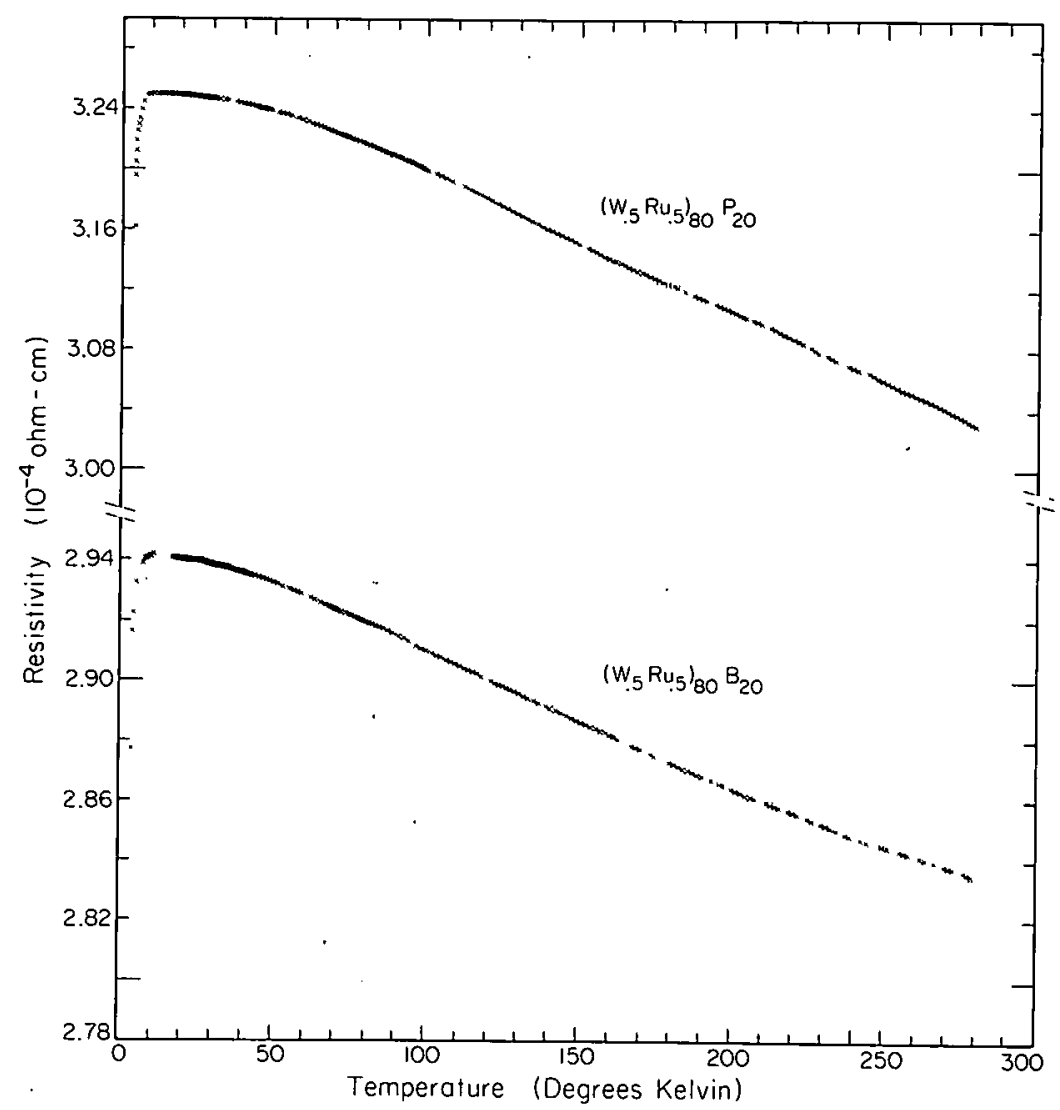

Fig. 6. Resistivity as a function of temperature for two refractory. metal glasses. 


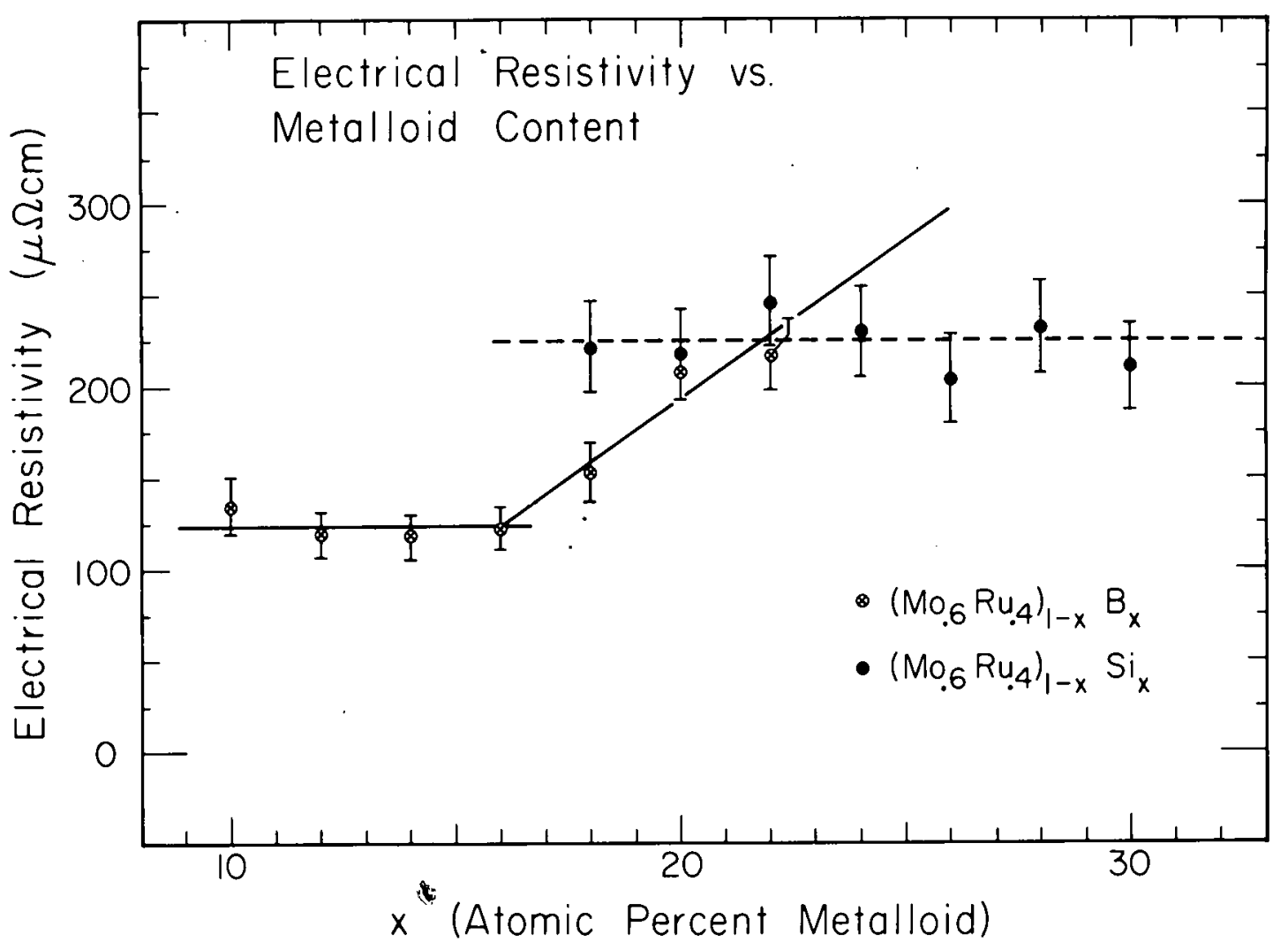

Fig. 7. Resistivity as a function of metalloid concentration at room temperature for $\left(\mathrm{Mo}_{0.6} \mathrm{Ru}_{0.4}\right)_{1-x^{\mathrm{M}} \mathrm{x}}$ alloys. 
independent of $x$ to within experimental error. For the alloys with $B$, $\rho_{0}$ is independent of $x$ for $(0.10 \leq x \leq 0.16)$ but increases rapidly with $x$ for $x>0.16$. The discontinuity in the slope of the $\rho_{0}(x)$ plot near $x=0.16$ is of particular interest. Similar behavior has been previously observed in other transition metal-metalloid glasses ${ }^{16,27}$ and suggests a possible change in the electronic structure of the glass near $x=0.16$ at.\% $B$. For transition metals, a two-band model of conduction is appropriate. Here, the electrical conductivity $\sigma_{0}=\rho_{0}^{-1}$ is given by a sum of two terms $\sigma_{0}=\sigma_{s}+\sigma_{d}$ arising from the s-band and d-band contributions. On the basis of previous studies of transport properties of crystalline transition metals, it is probable that the free electron like contribution $\sigma_{s}$ dominates the normal state transport properties of these materials. This will be discussed further in the next section.

D. Mechanical Behavior - Hardness and Embrittlement

Vickers hardness (V.H.) data were obtained for a large number of the alloys studied. The data are summarized in Table IV. For each sample, the diamond pyramid test was repeated six or more times and the hardness value listed is an average taken over the values obtained from these trials. All of the samples tested have rather high hardness values. Glasses containing only $B$ as the metalloid constituent exhibited the highest values. For the (Mo.$\left._{.}{ }^{\mathrm{Ru}} \cdot{ }_{.4}\right){ }_{7-x^{\mathrm{B}} \mathrm{x}}$ series, values of $\mathrm{VH}$ ranging up to $1600\left(\mathrm{~kg} / \mathrm{mm}^{2}\right)$ were observed while values ranging up to $1800\left(\mathrm{Kg} / \mathrm{mm}^{2}\right)$ were observed for $\left(W_{.} 6^{R u}{ }_{4}\right)_{1-x^{B}} x^{2}$ alloys. The variation of $V H$ with metalloid concentration for the two alloy series (Mo $\left..6^{R u} \cdot{ }_{4}\right)_{7-x^{B} x}$ and (Mo $\left.{ }_{.6}{ }^{R u}{ }_{.4}\right)_{1-x} \mathrm{Si}_{x}$ are shown in Fig. 8. In both cases, VH can be seen 
TABLE IV. Vicker's hardness as a function of metalloid content for several glasses. The last column summarizes results of ductility test (see text).

\begin{tabular}{|c|c|c|}
\hline Alloy & $\mathrm{VH}\left(\mathrm{k}_{\mathrm{g}} / \mathrm{mm}^{2}\right)$ & Ductility* \\
\hline$\left(\mathrm{Mo}_{\left.0.6^{R u_{0.4}}\right)}\right)_{-x^{\mathrm{B}} \mathrm{x}}$ & & \\
\hline$x=0.12$ & $1370 \pm 40$ & d \\
\hline 0.14 & $1260 \pm 70$ & $d$ \\
\hline 0.16 & $1420 \pm 70$ & $d-b$ \\
\hline 0.18 & $1440 \pm 30$ & $b$ \\
\hline 0.20 & $1470 \pm 40$ & b \\
\hline 0.22 & $1560 \pm 50$ & $b$ \\
\hline 0.24 & $1600-1800$ & $v b$ \\
\hline \multicolumn{3}{|l|}{$\left(\mathrm{Mo}_{0.6}{ }^{\mathrm{Ru}} 0.4\right)_{1-\mathrm{x}} \mathrm{Si}_{x}$} \\
\hline$x=0.18$ & $957 \pm 60$ & $v b$ \\
\hline 0.20 & $1080 \pm 90$ & b \\
\hline 0.22 & $1147 \pm 45$ & b \\
\hline 0.24 & $1118+65$ & b \\
\hline 0.26 & $1150 \pm 60$ & b \\
\hline 0.28 & $1250 \pm 90$ & $b$ \\
\hline 0.30 & $1220 \pm 65$ & $v b$ \\
\hline 0.32 & $1255 \pm 65$ & $v b$ \\
\hline \multicolumn{3}{|l|}{$\left(P_{0.6}{ }^{C u_{0.4}}\right)_{1-x} P_{x}$} \\
\hline$x=0.15$ & $\underline{ }$ & d \\
\hline 0.16 & 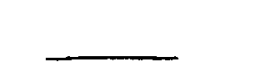 & $d-b$ \\
\hline 0.17 & $\ldots$ & b \\
\hline 0.18 & 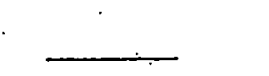 & b \\
\hline 0.19 & 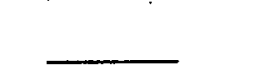 & b \\
\hline 0.20 & L. & b \\
\hline 0.22 & $\ldots$ & b \\
\hline 0.24 & 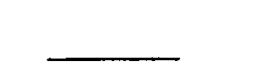 & $v b$ \\
\hline 0.26 & $\overline{-}$ & $v b$ \\
\hline$\left(w_{0.5^{R u_{0}} 0.5}\right)_{0.8^{\mathrm{B}} 0.2}$ & $1500 \pm 100$ & $b$ \\
\hline 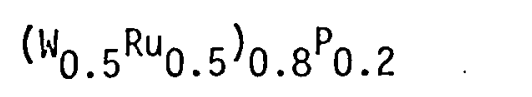 & $1120 \pm 50$ & $v b$ \\
\hline 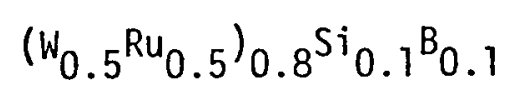 & $1190 \pm 50$ & $b$ \\
\hline
\end{tabular}




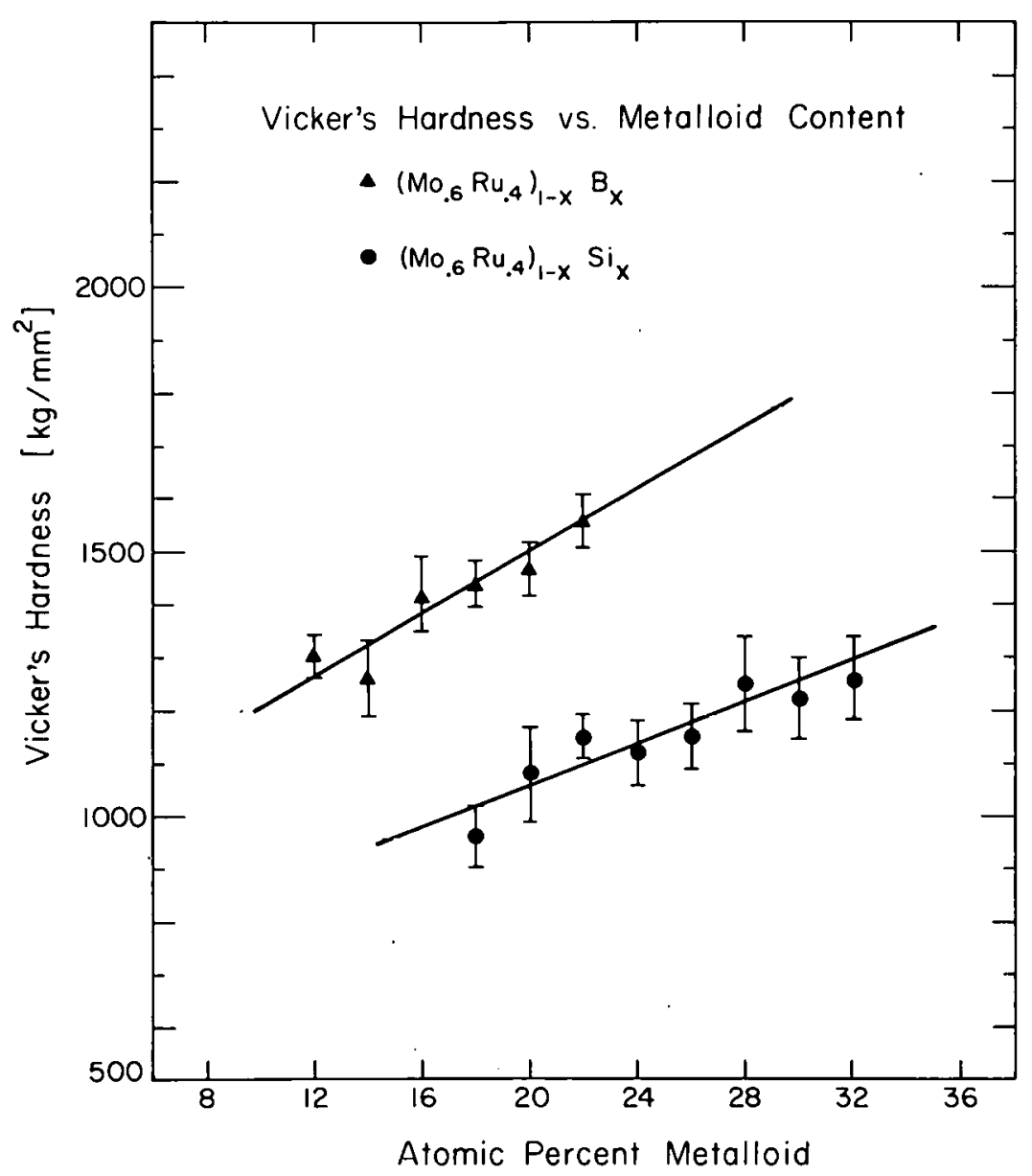

Fig. 8. Vicker's hardness as a function of metalloid concentration for $\left(\mathrm{Mo}_{0.6^{\mathrm{Ru}}} \mathrm{u}^{4}\right)_{1-\mathrm{x}_{\mathrm{x}}^{\mathrm{M}}}$ alloys. 
to be a strongly increasing fucntion of $x$. Hardness is closely related to deformability. The curves suggest a rapid loss of deformability with increasing metalloid concentration. The various regimes of deformation in amorphous materials have been described by several authors. $28,29,30$ The hardness tests involve mainly heterogeneous flow with deformation occuring in local shear bands. 28 In the final section of this paper, an attempt will be made to relate the variation of $\mathrm{VH}$ with $\mathrm{x}$ to the amount of "excess volume" present in the sample. If the suggestions made in Section III (b) are correct, then one might explain the observed variation of hardness with $x$ in terms of the "excess volume" arising in a metalloid deficient matrix.

Most of the alloys used in this study were observed to be rather brittle. Sample foils of these alloys are observed to fracture easily as a result of bending. On the other hand, a few of the alloys were found to exhibit considerable ductility and flexibility. Notably, samples of the (Mo $\left.{ }_{.6}{ }^{\mathrm{Ru}}{ }_{4}\right)_{1-x^{\mathrm{B}} \mathrm{x}}$ series with $\mathrm{x}<0.18$ show both flexibility and ductility and are not prone to brittle fracture. A simple test was used to make these observations more quantitative. A small strip (1-2 mm in width) was cut from a foil and then bent around the edge of a razor blade. Samples which can be permanently deformed in this manner are termed ductile; samples which fracture during the test are termed brittle. Samples which fracture on slight bending (with a radius of curvature of several millimeters) are termed very brittle. Table IV. summarizes

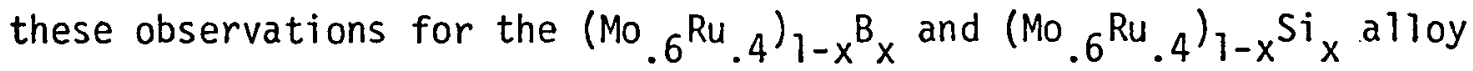
series. It is clear that a "ductile to brittle" transition occurs in the former alloy series with increasing $x$. All alloys of the latter series were found to be brittle or very brittle. A similar series of tests 
were carried out on the (Pd $\left.{ }_{6}{ }^{\mathrm{Cu}}{ }_{.4}\right){ }_{7-x} \mathrm{P}_{x}$ alloy series referred to previously. Again, a conspicuous ductile to brittle transition is observed with increasing $x$ as seen in Table IV. These observations will be discussed further in the following section.

IV. DISCUSSION AND COMPARISON WITH PREVIOUS WORK

\section{A. Structure and Related Properties}

Efforts to understand the structure of metallic glasses have focused mainily on the comparison of experimentally determined RDF's with those calculated using various mechanical or computer generated models. It is generally accepted that DRPHS models provide a rather good description for glasses of the (TM) $1-x^{M} x$ type. Cargi $17^{6}$ has summarized the status of this work in a recent review article. Recently, neutron diffraction techniques 31,32 and extended $x$-ray absorption fine structure measurements 33,34 have been used to provide additional information concerning chemical short range order in these materials. These results indicate an absence of $M-M$ nearest neighbor pairs and give coordination numbers for both $T M$ and $M$ sites in the amorphous matrix. Polk's suggestion 20,21 that $M$ atoms occupy low coordination interstitial sites with 7-9 nearest neighbors within a DRPHS of roughily 12-fold coordinated TM sites is at least partially confirmed by these results. The RDF's computed for the refractory metal glasses of the present study suggest that these alloys have a structure very much like that of other (TM) $1-x{ }^{M} x$ glasses. The arrangement of TM atoms is well described by the simplest DRPHS model of Bernal and Finney ${ }^{3}$ as discussed in Section III A. In the absence of more refined structural data, it is reasonable to assume that the chemical short-range order of these 
refractory glasses is probably similar to that of other $\mathrm{TM}_{1-x} M_{x}$ glasses. In particular, the coordination number of the TM sites and the low probability of M-M pairs are likely to be general features. 28,35

In Section III B, it was shown that a glassy TM phase can be characterized as having a mean atomic volume $\bar{V}$ which is $5 \%$ greater than that observed for a crystalline close-packed TM phase at room temperature. When a metalloid element of metallic volume $V_{B}^{0}$ is added to this matrix, this "excess volume" decreases in the $T M_{1-x} M_{X}$ glass. The volume $V_{B}^{0}$ can be determined either from the metallic radius of $M$ or from crystallographic data for intermetallic TM-M compounds having composition near that of the glass. These two estimates of $V_{B}^{O}$ are in close agreement. Near the upper limit of compositions for which a glass is obtained, the "excess volume" was observed to vanish (i.e. $\bar{V}_{B} \rightarrow V_{B}^{0}$ ) in all cases analyzed. A volumetric packing fraction can be defined in terms of the volumes $V_{A}^{0}, V_{B}^{0}$, and $\bar{V}$ as

$$
\eta_{V}=\left[\frac{(1-x) V_{A}^{0}+x v_{B}^{0}}{\bar{V}}\right] \eta_{c p}
$$

and thus ranges from 0.705 for the physically inaccessible. TM glass to $\sim 0.740=n_{\mathrm{cp}}$ near the upper limit $x_{M}$ of the glass forming range. Unlike the usual packing fraction, $n_{V}$ cannot be interpreted in terms of hard spheres in contact. The relative "excess volume" per atom can be ex- = pressed in terms of this volumetric packing fraction as

$$
v_{e}=\left[\frac{n_{c p}}{n_{V}}-1\right]
$$

where $v_{e}$ is observed to vary in a roughly linear manner from 0.05 to 0.0 as $x$ varies from 0 to $x_{M}$. If $v_{e}$ were to be interpreted in terms of 
vacancies, one could then assign the equivalent of $v_{e}$ vacancies per atom in the metallic glass. This analogy suggests that the "excess volume" occurs in localized regions of space. This need not be the case. The actual distribution of "excess volume" in the glass may take a variety of forms.

To explore the consequences of $v_{e}$, one can extend the analogy with vacancies. One well known effect of vacancies in a crystalline metal or intermetallic compound is the unusual dependence of the lattice parameter on vacancy concentration. The early work of Bradley and Taylor ${ }^{36}$ on the transition metal-non transition metal compound BNiAl is a good example. This compound exhibits. a homogeneity range from 45-60 at.\% Ni. Random substitution of $\mathrm{Ni}(\mathrm{Al})$ on $\mathrm{Al}(\mathrm{Ni})$ sites could accompany deviations from stoichiometry and would be expected to lead to a steady decrease in lattice parameter $\mathrm{a}$ with increasing $\mathrm{Ni}$ content. Instead, $\mathrm{Ni}$ vacancies are observed on the Al-rich side of stoichiometry as established from density measurements. The lattice parameter falls sharply with decreasing $\mathrm{Ni}$ content for $\mathrm{Ni}$ deficient compositions. For $\mathrm{Ni}$-rich compositions the lattice parameter exhibits a decrease with increasing $\mathrm{Ni}$ content as expected for substitutional atomic site disorder. The total variation of a with $\mathrm{Ni}$ content thus exhibits an unexpected maximum which derives from the vacancy formation. Similar behavior is found for the lattice parameter of many TM-M interstitial compounds of the type first described by Hägg ${ }^{9}$ where $M$ site vacancies are observed for M-poor deviations from stoichiometry. Examples are the $\mathrm{NaCl}$-type phases of TiN, TiC, and TiO. Ehrlich has given a detailed discussion for the case of TiN. ${ }^{37}$ One can examine the present data to determine if similar effects result from "excess volume" in M-poor glasses. The variation of the first nearest 
neighbor distance (NND) with M concentration is in this case analogous to the variation of lattice parameter in a crystal. For the case of

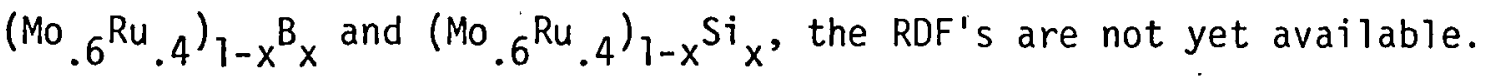
From $x$-ray scans, we can, however, estimate an effective NND from the position of the first diffraction maximum using the formula 38

$$
\text { NND }=(1.23 \lambda) /\left(2 \sin \theta_{m}\right)
$$

where $\theta_{\mathrm{m}}$ is the angular position of the first maximum in the experimental interference function and $\lambda$ the $x$-ray wavelength. The results are shown in Fig. 9. Surprisingly, the NND exhibits a maximum as a function of $M$ concentration. Dixmier ${ }^{39}$, computed the RDF's for a series of

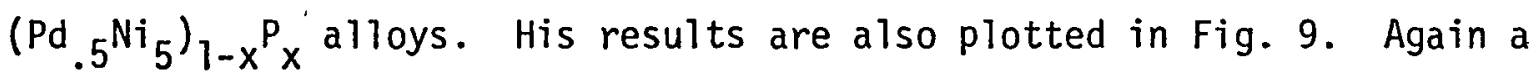
maximum occurs in the variation of NND with $M$ concentration. By analogy with the crystalline case, these observed maxima suggests vacancy-like defects for metalloid concentrations on the M-poor side of the maxima. If we use $x_{c}$ (critical concentration) to refer to the $x$ value at which these maxima occur, then these data suggest that $x_{c}$ is analogous to the stoichiometric composition of an intermetallic compound. The electrical resistivity measurements further support this picture. The variation of the absolute resistivity (at room temperature) $\rho_{0}$ with $x$ observed for (Mo ${ }^{\mathrm{Ru}}{ }^{\mathrm{R}}{ }_{4}$ ) $1-\mathrm{x}^{\mathrm{B}} \mathrm{x}$ shows an abrupt.discontinuity in slope at $\mathrm{x} \approx 0.16-0.18$ (Fig.7), the same value of $x$ for which the NND shows a maximum. For $\left(\mathrm{Pd} .6^{\mathrm{Ni}}{ }_{4}\right)_{1-x^{\mathrm{P}} \mathrm{x}}$ a similar discontinuity in $\rho_{0}$ is observed for $x \approx 0.22$ as seen in the data of Boucher 27 shown in Fig. 10. Again this coincides with the position of the maximum in the plot of NND vs $x$. For $\left(M_{0}, 6^{\mathrm{Ru}}{ }_{4}\right)_{1-x} \mathrm{Si} x$, such a discontinuity in $\rho_{0}$ is not apparent near $x_{c}$; however, $x_{c}$ is very close 


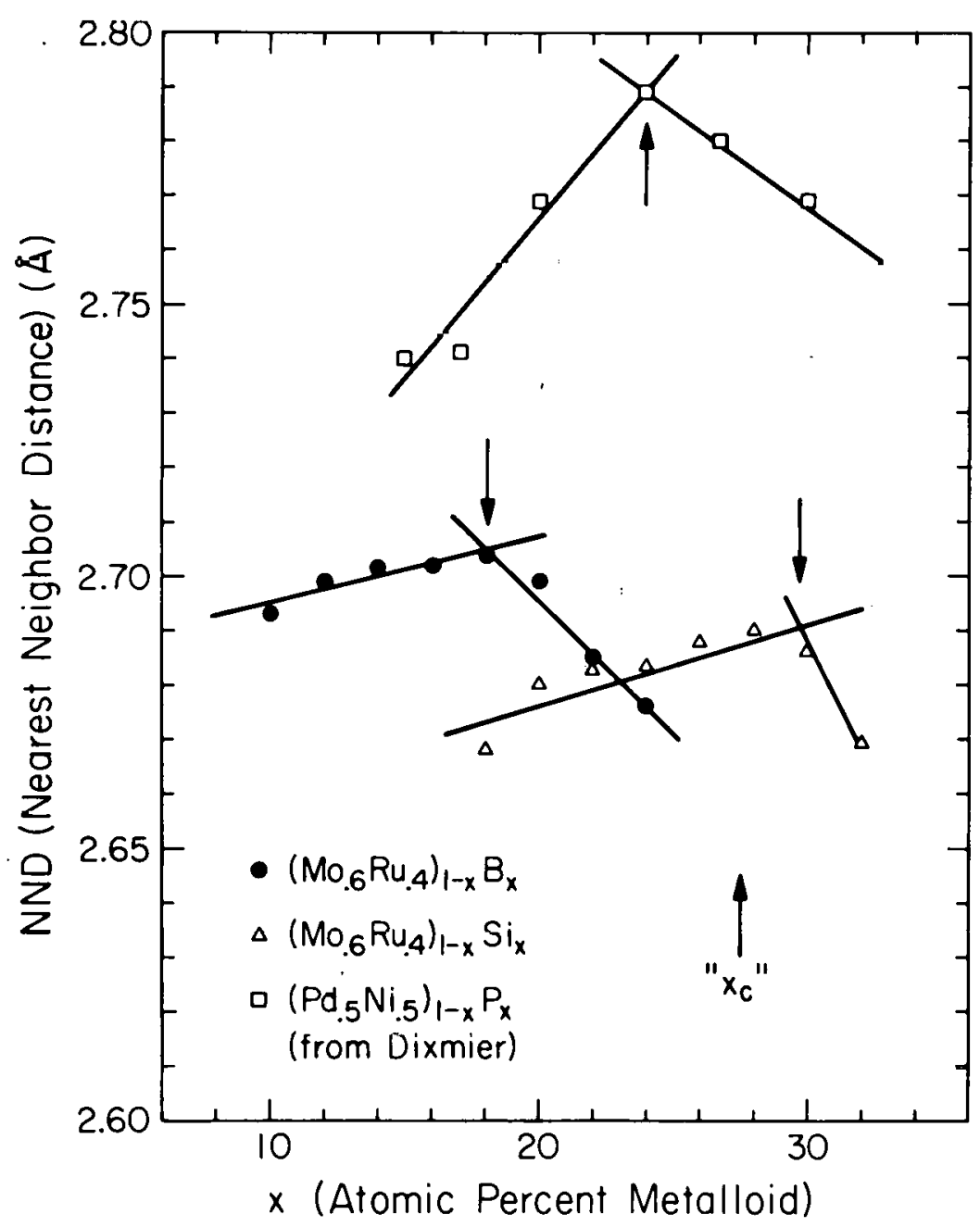

Fig. 9. Nearest neighbor distance as a function of metalloid concentration for several (TM) $1-x_{x}{ }^{M}$ glasses. For Mo-Ru base glasses, eqn. (10) was used together with the experimental $x$-ray diffraction scan to estimate the NND. For $\left(\mathrm{Pd}_{0.5} \mathrm{Ni}_{0.5}\right)_{1-x} \mathrm{P}_{x}$, the radial distribution functions of Dixmier ${ }^{39}$ were used to give the most probable NND. 


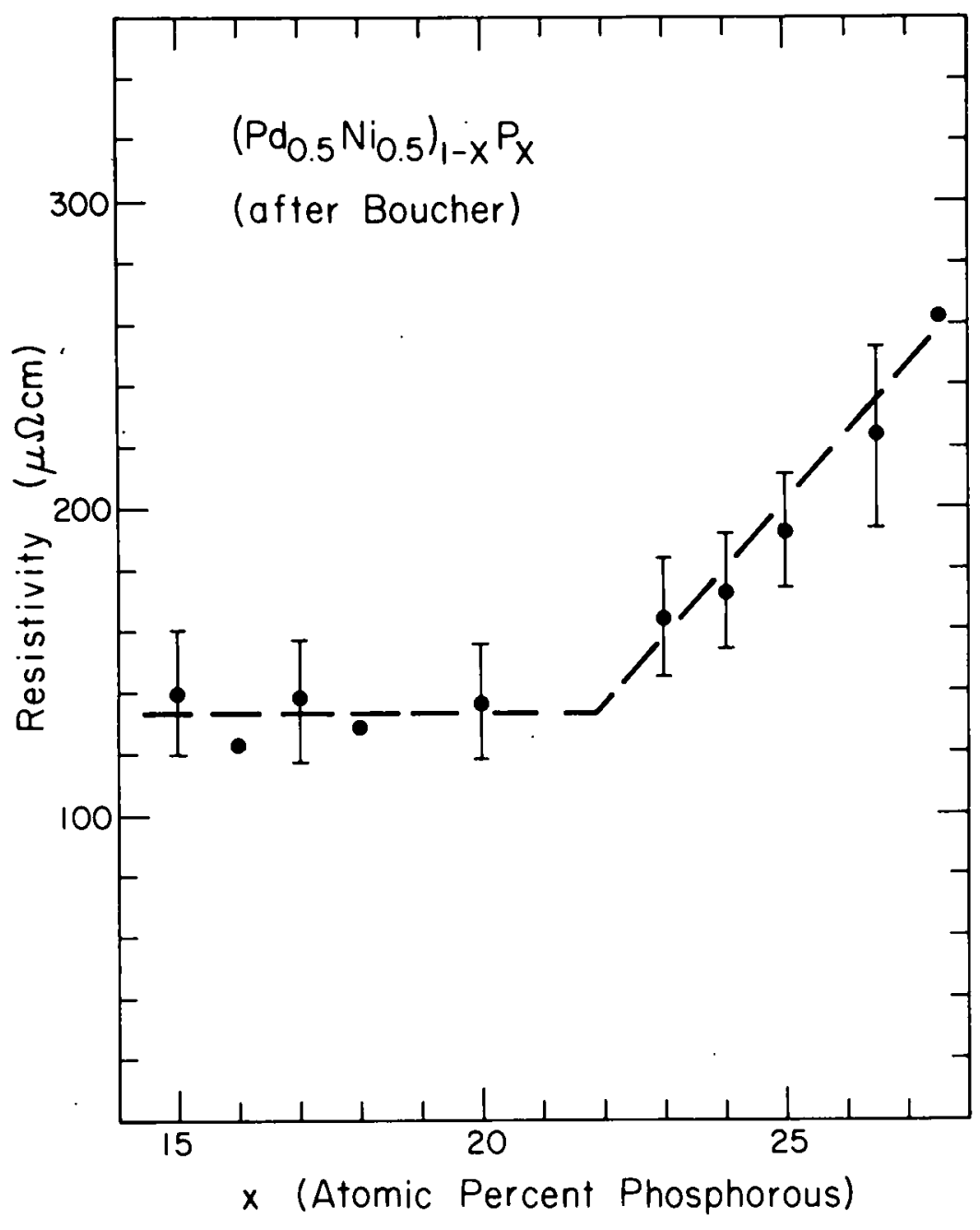

Fig. 10. Resistivity as a function of phosphorus concentration for $\left(\mathrm{Pd}_{.} 5^{\mathrm{Ni}} \cdot 5_{1-x^{\mathrm{P}} \mathrm{x}}\right.$ alloy. (Taken from Boucher ${ }^{27}$ ) 
to the upper limit of the amorphous phase field so that the behavior could easily be obscured in the experimental data.

The above observations strongly suggest an ideal amorphous structure which has a "preferred composition" $x_{c}$. For $x<x_{c}$, the glass exhibits a "vacancy-like" defect present with concentration proportional to $v_{e}$. For $x>x_{c}$, the data suggest that another type of defect occurs, the nature of which is as yet unclear. The rapid rise in $\rho_{0}$ for $x>x_{c}$, implies that this latter defect strongly influences electronic scattering and thus electronic transport properties of the glass whereas the "vacancy-like" defect appears to have little influence on electronic transport.

There are additional types of evidence which suggests a similar behavior in other metallic glasses. Logan 40,41 has studied the properties of electro-deposited $\mathrm{Fe}_{\mathrm{I}-\mathrm{x}} \mathrm{P}_{\mathrm{x}}$ alloys for $0.15<\mathrm{x}<0.25$ and observed a discontinuous change in $\rho_{0}$ vs $x$ near $x=0.17$. The Mössbauer spectra of $\operatorname{Logan}^{42}$ provide additional evidence. For $x<0.17$, a quadropolar splitting of the $\mathrm{Fe}^{57}$ line is observed. This splitting decreases with $\mathrm{x}$ and vanishes at $x \approx 0.17$ where a narrow single line is observed. For $x>0.17$ this single line broadens with increasing $x . \operatorname{Logan}^{42}$ interpreted this data to imply a well defined chemical and topological short range order (CSRO and TSRO) near $x \approx 0.17$. These observations are again consistent with the above ideas.

\section{B. Mechanical Behavior}

The concept that an "ideal" amorphous structure exists with metalloid content $x_{c}$ and "vacancy-like" defects for $x_{<} x_{c}$ can also provide an interesting framework in which to analyze the mechanical behavior of these 
materials. In section III $D$, the transition from ductile to brittle behavior with increasing $x$ was described. It was pointed out that this transition is accompanied by increasing hardness of the material. Both of these properties are related to the deformability of these glassy metals. Spaepen ${ }^{28}$ has recentiy given a review of the structure and deformation behavior of metallic glasses. He has discussed a model of deformation behavior involving defect controlled flow. The basic defect is a site of excess volume $V_{0}$ which upon rearrangement produces a local shear strain $\gamma_{0}$. The strain rate is given by an equation of the form ${ }^{28}$

$$
\dot{\gamma}=n V_{0} \gamma_{0} K_{0}
$$

where $n$ is the defect density, and $k_{0}$ the frequency of rearrangement at a defect site. The value of $K_{0}$ can be expressed in the form

$$
K_{0}=\nu_{D} \exp \left(-\frac{\Delta G^{\prime}}{K_{B} T}\right) \sinh \left(\frac{\tau \gamma_{0} V_{0}}{K_{B} T}\right)
$$

where $\Delta G^{\prime}$ is an activation energy for atomic rearrangement, $\nu_{D}{ }^{a}$ characteristic atomic vibration frequency, and $\tau$ the applied stress. These equations then predict a strain rate sensitivity for the case of homogeneous flow given by

$$
m=\frac{\alpha \ln \dot{\gamma}}{\alpha \tau}=\frac{\tau \gamma_{0} V_{0}}{K_{B} T} \operatorname{coth}\left(\frac{\tau \gamma_{0} V_{0}}{K_{B} T}\right)
$$

In the free volume theory of Turnbull: and Cohen ${ }^{43}$, the defect concentration is given by

$$
n=\frac{1}{r} \exp \left(-\frac{\gamma^{\prime} V^{\star}}{V_{F}}\right)
$$


where $V^{*}$ is the minimum size of a hole required to accomodate a neighboring atom which jumps into the hole, $\gamma^{\prime} \approx 1, \Omega=$ mean atomic volume, and $v_{f}=$ free volume per atom. This equation is applicable for temperature near or above the glass transition temperature $T_{g}$. The model of Cohen and Turnbull describes a monotonic metallic liquid near $T_{g}$. The free volume $v_{f}$ is assumed to depend on temperature. For a $T_{7-x} M_{x}$ alloy, $v_{f}$ could also depend on composition. The temperature dependence of $v_{f}$ in the monatomic system is approximately given by $28,43 v_{f}=\alpha\left(T-T_{0}\right) \Omega_{0}$ for $T \sim T_{g}$. Here $T_{0}$ is an appropriate reference temperature at which the thermal free volume is effectively zero. On the basis of the variation of observed "excess volume" per atom $v_{e}$ with $x$ in $\mathrm{TM}_{7-x} M_{x}$ glasses, one can postulate a composition dependent contribution to $v_{f}$. The volume $v_{e}$ is not equivalent to free volume in the sense defined by Turnbull and Cohen, but rather is a sum of both the free volume and an excess volume which cannot be "redistributed without substantial increase in the internal energy of the system. The latter volume cannot be regarded as free volume. On the other hand, from the variation of $v_{e}$ with $x$, it is reasonable to assume that $v_{f}$ varies with $x$. The following expression is proposed for $v_{f}$ :

$$
v_{f}=\alpha\left(T-T_{0}\right) \Omega_{0}+\beta\left(X_{M}-x\right) \Omega_{0} \quad\left(x<X_{M}\right)
$$

where

$$
\beta \approx \frac{f v_{e}^{0}}{x_{M}} \approx \frac{0.05}{0.2} f=0.25 f
$$

and $f$ is a factor less than but of order 1 . For a glass quenched from the liquid state, $T$ should be replaced by a fictive temperature $T_{f}$ which 
describes the configurational state which is frozen in. Thus, one obtains

$$
v_{f}=\alpha \cdot\left(T_{f}-T_{0}\right) \Omega_{0}+\beta\left(x_{M}-x\right) \Omega_{0}
$$

Homogeneous flow should then be described by eqn. 9 with a defect concentration given by eqn. 14. We could refer to the two terms in eqn. 15 for $v_{f}$ as the thermal and structural components of the free volume. The case of heterogeneous flow is more complex. Spaepen ${ }^{28}$ has argued that heterogeneous flow is governed by a steady state concentration of defects produced by local stress driven creation of free volume in shear bands. He gives the steady state defect concentration as

$$
\ln n=\frac{S v^{*}}{2 k_{B} T n_{D}}\left[\cosh \left(\frac{\tau \Omega}{2 k_{B} T}\right)-1\right]^{-1}
$$

where $S=2 \mu(l+V)$ with $\mu=$ shear modulus, $v=$ Poisson's ratio, $v^{*}$ is the minimum volume of a defect which permits atomic jumps, and $n_{D}$ is the number a jumps necessary to annihilate an amount of free volume $v^{*}$. This equation gives a defect concentration which does not depend on the free volume of initial structure directly. However, several factors in this equation do depend on the initial structure. In particular $\mu$ (and thus S) and $n_{D}$ may depend on intial structure. It is likely that $\mu$ will depend on the structural component of the free volume defined in eqn. 14. One would expect $\mu$ to decrease with excess volume. Thus, for a given stress $\tau$, a higher defect concentration should be produced when the structural component of "excess volume" is large. Heterogeneous flow should thus be facilitated by "excess volume".

The "ductile to brittle" transition observed with increasing $x$ is 
likely to be related to the "excess volume" through the above considerations. For $x \geqslant x_{c} v_{e} \approx 0$, and both homogeneous and heterogeneous flow will be inhibited by comparison with the case where $x<x_{c}$. The increasing Vicker's Hardness can also be interpreted. As $x$ increases, deformability decreases. Thus hardness should also increase with increasing $x$. Although the present discussion does not constitute a rigorous account of the mechanical behavior, it does suggest that there are rather general considerations regarding the relationship of mechanical behavior and the systematic variation of $v_{e}$ with metalloid concentration. One can speculate that this systematic variation is common to $\mathrm{TM}_{1-x} M_{x}$ glasses. The "ductile to brittle" transition should then also be a common feature of these glasses. One can speculate that for sufficiently small $x$, all $T M_{1-x} M_{x}$ glasses should exhibit ductility owing to a large structural excess volume which facilitates defect controlled flow. These ideas will be further discussed in an upcoming publication.

\section{Superconductivity and Electronic Properties}

The variation of $T_{c}$ with $x$ for amorphous alloys of the (Mo ${ }_{6}{ }^{R u}{ }_{.4}$ ) $1-x^{M} x$ series was shown in Fig. 4. According to the analysis presented in reference 3 , one expects that the d-band density of states near the Fermi level $D_{d}(0)$ is the dominant factor which governs the variation of $T_{c}$ in the refractory metal glasses. The variation of metalloid concentration will effect $D_{d}(0)$ in several ways. First, the presence of metalloid atoms reduces the density of the transition ions. Assuming a tight-bind model in which the atomic-like d-orbitals are broadened into a rather featureless band (ref. 3 ), one would expect $D_{d}(0)$ to be proportional to the number of transition ions per unit volume. Addition of metalloid 
atoms "dilutes" the d-band. For isoelectronic metalloids such as Si and Ge (or $P$ and $A s)$, the larger metalloid should dilute $D_{d}(0)$ more rapidly. This expectation agrees with the observation that $T_{c}$ is depressed more rapidly by the larger metalloid (Fig. 4).

Electron transfer effects which lead to a filling or emptying of d-Tevels through electronic interactions of transition atoms with metalloid atoms must also be taken into account. Evidence that such effects are important comes from the observation that metalloids belonging to the same series (e.g. Si and $P$ ) depress $T_{c}$ with quite different slopes although such metalloids have comparable atomic radii. Electron transfer effects will generally lead to a net increase or decrease in the occupation of the d-band. This in turn will influence $D_{d}(0)$. A detailed analysis of this effect is not possible from the limited amount of data. available and must await further experimental results.

Recently, several attempts have been made to understand the variation of electrical resistivity of metallic glasses with temperature and composition. $^{26}$ According to several authors 26,44 , the Ziman theory and its' extensions provide an adequate description of the variation absolute resistivity in (TM) $1-x^{M} x$ glasses. In addition, it is claimed that the sign of the temperature coefficient of resistivity $\alpha$ is accounted for in using the extended Ziman picture. Tsuei $i^{45}$ has recently proposed an alternative explanation of the variation of $\alpha$ based on a "Kondo-type" Hamiltonian formalation described by Cochrane et al. ${ }^{46}$ Esposito et al ${ }^{47}$ have recently illustrated that caution must be exercised in applying the Ziman theory to metallic glasses containing strong scattering transition ions.

The data obtained in the present study suggest that the chemical and 
and topological short range order of metallic glasses may influence the electrical resistivity in a more subtle manner than previously recognized. The discontinuous change in the variation of resistivity with metalloid concentration (Fig. 7 and Fig. 10) has been interpreted above in terms of deviations from an ideal amorphous structure. For metalloid deficient compositions $\left(x<x_{c}\right)$, it has been argued that "vacancy-like" defects are present whereas another type of defect occurs for excess metalloid concentrations $\left(x>x_{c}\right)$. From the variation of $\rho_{0}$ with $x$, it would seem that these two defect types effect $\rho_{0}$ in quite different ways. The "vacancy-1ike" defects do not appreciably effect $\rho_{0}$ increases rapidly with the concentration of defects of the second type. It is not obvious that the Ziman theory or its extensions can easily account for this behavior. The presence of defects should be reflected in the reduced interference function $S(q)$ and as such could in principle be taken into the Ziman theory. On the other hand, it is difficult to see how the sharp discontinuity in the variation of $\rho_{0}$ with $x$ can arise naturally in the Ziman picture. These data suggest that more emphasis be placed on the details of the atomic scale structure in analysing electronic properties. 


\section{REFERENCES}

*Work supported by Department of Energy, Contract No. EY-76-C-03-0822.

1. W. Klement, R. H. Willens, and P. Duwez, Nature, 187, 869 (1960).

2. An extensive collection of articles is published in Proc. III Int. Conf. on Rapidly Quenched Materials, Ed. by B. Cantor, (British Metals Society, London) 1978.

3. W. L. Johnson, S. J. Poon, J. Durand, and P. Duwez, Phys. Rev. B, $18,201 \cdot(1978)$.

4. J. D. Bernal, Nature (London), 183, 141 (1959); J. D. Bernal in "Liquids: Structures, Properties, and Solid Interactions" (T. J. Hugel ed.) p. 25 (Elsevier, Amsterdam) 1965; J. L. Finney, Proc.

- Roy. Soc., Ser. A319, 479 (1970).

5. G. S. Cargill III, J. Appl. Phys., 41, 12 (1970).

6. G. S. Cargill III, Solid State Phys., 30, 227 (1975).

7. A. R. Williams and W. L. Johnson, to be published separately.

8. D. Turnbu11, Scripta Met., 11, 1131 (1977).

9. G. Hägg, Z. Phys. Chem., B6, 221 (1929) Ibid., B12, 33 (1931).

10. L. A. Davis in Metallic Glasses, p. 190, (American Society for Metals, Metals Park, Ohio) (1978).

11. H. J. Leamy, H. S. Chen, and T. T. Wang, Met. Trans., 3, 699 (1972). 
12. H. S. Chen, S. D. Ferris, E. M. Gyorgy, H. J. Leamy, and R. C. Sherwood, App1. Phys. Letters, 26, 405 (1975).

13. H. S. Chen and D. E. Polk, J. Non-Cryst. Solids, 15, 174 (1974).

14. P. Duwez, Progress in Solid State Chemistry, (Pergamon, Oxford, 1966) Vol. 3.

15. W. B. Pearson, Handbook of Lattice Spacings and Structure of Metals, (Pergamon, 0xford; 1967) Vol. 2.

16. G. Tangonan, Ph.D. Thesis, California Institute of Technology, 1976.

17. W. H. Shu11, D. G. Naugle, S. J. Poon, and W. L. Johnson, Phys: Rev. B, 18,3263 (1978).

18. C. H. Bennett, J. Appl. Phys., 43, 2727 (1972).

19. D. J. Adams and A. J. Matheson, J. Chem. Phys., 56, 1989 (1972).

20. D. E. Polk, Scr. Met., 4, 117 (1970).

21. D. E. Polk, Acta. Met., 20, 485 (1972).

22. E. Domb and W. L. Johnson, J. Low Temp. Phys., 33, 29 (1978).

23. M. M. Collver and R. H. Hammond, Phys. Rev. Letters, 30, 92 (1973).

24. 0. Meyer, New Uses of Ion Accelerators, Ed. by J. F. Ziegler, (Plenum Press, New York, 1974) p. 15.

25. E. Helfand and N. R. Werthamer, Phys. Rev. Letters, 13, 686 (1974); Ibid., Phys. Rev., 147, 288 (1966). 
26. J. M. Ziman, Adv. in Phys., 16, 551 (1967); L. V. Meisel and P. J. Cote, Phys. Rev. B, 15, 2970 (1977); S. R. Nagel, Phys. Rev. B, 16, 1694 (1977).

27. B. Y. Boucher, J. Non-Cryst. Solids, Z, 277 (1972).

28. F. Spaepen, Proc. III Int. Conf. of Rapidly Quenched Metals, Ed. by B. Cantor, Vol. II, p. 253, (British Metals Society, London, 1978).

29. M. F. Ashby and H. J. Frost, Constitutive Equations in Plasticity, Ed. by A. S. Argon, p. 117. (M.I.T. Press, Cambridge, Mass., 1975).

30. T. Masumoto and R. Maddin, Acta. Met., 19, 725 (1971).

31. J. F. Sadoc and J. Dixmier, Proc. II Int. Conf. on Rapidly Quenched Metals, Ed. by B.C. Giessen and N. J. Grant, (Elsevier Sequoia, Lausanne, Switz., 1975) Vol. II.

32. T. Fukunaga, M. Misawa, K. Fukamichi, T. Masumoto, and K. Suzuki, Proc. III Int. Conf. on Rapidly Quenched Metals, Ed. by B. Cantor, Vol. II, p. 329 (British Metals Society, London, 1978).

33. T. M. Hayes, J. W. Allen, J. Tauc, B. C. Giesson, and J. J. Hauser, Phys. Rev. Letters, 40, 1282 (1978).

34. J. Wong, F. W. Lytle, R. B. Greegor, H. H. Liebermann, J. L. Walter, and F. E. Luborsky, Proc. III Int. Conf. on Rapidly Quenched Metals, Ed. by B. Cantor, Vol. II, p. 345 (British Metals Society, London, 1978).

35. D. S. Boudreaux, Amorphous Magnetism II, Ed. by R. A. Levy and R. Hasegawa, p. 463, (Plenum Press; New York, 1977). 
36. A. J. Bradley and A. Taylor, Proc. Roy. Soc., 159, 56 (1937).

37. P. Ehrlich, Z. Anorg. Chem., 259, II, 28 (1949).

38. A. Guinier, X-ray Diffraction, Chapter 3, (W. H. Freeman and Company, San Francisco, 1963).

39. J. Dixmier and P. Duwez, J. Appl. Phys., 44, 1189 (1973).

40. J. Logan, Phys. Stat. Sol., 32, 361 (1975).

41. J. Logan and M. Yung, J. of Non-Cryst. Sol., 21, 151 (1976).

42. J. Logan and E. Sun, J. of Non-Cryst. Sol., 20, 285 (1976).

43. M. H. Cohen and D. Turnbul1, J. Chem. Phys., 31, 1164 (1959);

D. Turnbul1 and M. H. Cohen, J. Chem. Phys., 34, 120 (1961).

44. G. Busch and H. Güntherodt, Solid State Physics, Vol. 29, Ed. by H. Ehrenreich, F. Sietz, and D. Turnbull, (Academic Press, New York, 1975) p. 235.

45. C. C. Tsuei, Bul1. Am. Phys. Soc., 22, 322 (1977).

46. R. W. Cochrane, R. Harris, J. 0. Strom-01son, and M. J. Zuckermann, Phys. Rev. Letters, $\underline{35}, 676$ (1975).

47. E. Esposito, H. Ehrenreich, and C. G. Gelatt, Jr., Phys. Rev. B, 18, 3913 (1978). 